\title{
Evolution of the flax cell wall composition during development and after gravitropism by synchrotron fluorescence imaging
}

Johnny Beaugrand ${ }^{1}$, Camille Goudenhooft ${ }^{2}$, Camille Alvarado1, Marie-Francoise Devaux¹, Camille Rivard ${ }^{3,4}$, Sylvie Durand ${ }^{1}$, Hugo Chauvet $^{5}$, Matthieu Réfrégiers ${ }^{5}$, Fréderic Jamme ${ }^{5}$, Fabienne Guillon ${ }^{1}$, Christophe Baley², Alain Bourmaud ${ }^{2}$

${ }^{1}$ INRAE, UR1268 BIA, F-44316, Nantes, France

2 Univ. Bretagne Sud, UMR CNRS 6027, IRDL, F-56100 Lorient, France

${ }^{3}$ Synchrotron SOLEIL, LUCIA Beamline, F-91192 Gif-sur-Yvette, France

4 INRAE, UAR 1008 TRANSFORM, F-44316 Nantes, France

${ }^{5}$ Synchrotron SOLEIL, DISCO Beamline, F-91192 Gif-sur-Yvette, France

Corresponding authors: Johnny Beaugrand johnny.beaugrand@inrae.fr and Alain Bourmaud alain.bourmaud@univ-ubs.fr

\section{Abstract}

Flax lodging is an issue of great interest for producers due to its economic impact. To better understand its effects at the cell wall and stem scale, new knowledge regarding the cell wall composition dynamics during cell wall development and after a $90^{\circ}$ tilt bending stress is reported. Deep-Ultra Violet fluorescence emission (DUV) dynamics recorded at the Synchrotron SOLEIL-DISCO beamline by multichannel autofluorescence imaging is reported for five cellular wall types of flax stems after an artificially induced gravitropic reaction. Three flax growth development stages, namely, the vegetative stage (VS), the fast growth (FG) and the mature stage (MS), were selected in normal plants, referred to as the control plants, or in gravitropic-induced response plants, referred to as $90^{\circ}$ tilted plants. The cell wall compositions were monitored after excitation at a $275 \mathrm{~nm}$ wavelength, and the fluorescence emission was interpreted to exhibit a biochemical composition. Three proper bypass filters permitted the monitoring of proteins, hydroxycinnamate and lignin compounds in five distinguishable cellular types, namely, epidermis, bast fibre, cambium, and primary and secondary xylems. The quantitative fluorescent profile intensities were computed after image analysis, and compared to the control flax stems, we reported a systematically higher average intensity fluorescence (probability $>95 \%$ ) for the $90^{\circ}$ tilted plants. Moreover, the average stem fluorescence intensities were significantly different 
among the 3 developmental stages, with the youngest stage (VS) exhibiting on average $30 \%$ and $20 \%$ less fluorescence than the medium (FG) and mature (M) stages, respectively. In addition, the systematic fluorescence quantification of the 5 cellular stem types showed a non-homogeneous trend of the assigned biochemical components. The flax stem response to tilt impacted the xylem cellular type, while the bast fibres were arguably less affected by the protein, hydroxycinnamate and lignin contents. A complementary investigation was carried out on bast fibres by infrared microspectroscopy to explore the polysaccharide components not seen in deep UV fluorescence, and significant modifications were monitored.

Key words: Infrared microspectroscopy, Hydroxycinnamate, Proteins, Lignin, Polysaccharide 


\section{Introduction}

One of the oldest fibre plants used by humans is a flax plant (Linum Usitatissimum L.); traces of flax as far as back the prehistoric civilization in Egypt, ancient Babylonia, and Europe (Heer, 1873) have been verified. Flax, a crop of economic interest, has been used for textile applications, for new developments in the field of high-performance composites in terms of the mechanics (Bourmaud et al., 2018; Mohanty et al., 2018), and for additional functionalities such as acoustic properties, e.g., for violin design (Viala et al., 2018). Flax is the most famous of the 180 plants that belong to the genus Linum, and understanding both the flax cellular development dynamics and the most influential parameters on which it has an impact remains a priority to optimize the quality of flax fibres and the material thereof. Flax belongs to the dicotyledonous group (Ray F. Evert, 2006), and its development has been well documented and recently reviewed (Goudenhooft et al., 2019a). Basically, this temperate crop follows four identifiable growth stages and can be schemed on a cumulative growing degree-day scale, starting from $0^{\circ} \mathrm{C}$ as the sowing date and reaching $1,000^{\circ} \mathrm{C}$ at flax stem fibre maturity. From a description point of view, the beginning is the emergence of the plant, followed by the vegetative stage (VS). At 15-20 days of the VS, the flax plant reaches approximately $15-20 \mathrm{~cm}$ (approximately 250 growing degree days). Then, for approximately three weeks, FG takes place. At that time, the flax plant elongates up to several centimetres per day (Gorshkova et al., 1996); (Heller et al., 2015), reaching 80-90 $\mathrm{cm}$ over this fast FG stage (approximately 500 growing degree days). The flax stem reaches a final length of approximately $1 \mathrm{~m}$ (Gorshkova et al., 2003) at fibre maturity (M) (approximately 1000 growing degree days).

Some external stresses may impact the bast fibre yield and benefits, such as the lodging phenomenon (Goudenhooft et al., 2019b), a stress of economic importance due to its high impact on farmer incomes. In fact, lodging sometimes occurs within crop fields, complicating the flax harvest and decreasing yields. From a fundamental view, it is fascinating to note that flax stems can be restored from lodging through a gravitropism reaction under specific conditions, such as the plant response to gravity after tilting.

Goudenhooft et al. (Goudenhooft et al., 2019b) reported that according to the lodging conditions, significant variations in individual bast fibre mechanical performances were measured. The measured differences between the not-tilted flax fibres and tilted flax fibres decreased as the plant maturity progressed, with almost no difference between the nottilted /tilted flax fibres at plant maturity. Among the stem cell types, bast fibres are actors in the plant gravitropic reaction through the adjustability of their cell wall performance 
(Goudenhooft et al., 2019b), but the implication of other cellular types, such as xylem, has also been demonstrated, with a significant evolution of the xylem cell morphology and structure after the tilt stage (Ageeva et al., 2005). At the scale of the flax stem, the focus has often been on the bast fibres, which is the reinforcement element of the flax stem (Goudenhooft et al., 2018; Réquilé et al., 2018), and the bast fibre from the pulling side of the flax stems tilted at the VS and even displayed an increased cell diameter and an enlarged lumen (Ibragimova et al., 2017).

The dynamics of the composition of these bast fibres are still ongoing, i.e., for biochemical research, bast fibres have been chemically extracted from cell wall polysaccharides and characterized in depth (Rihouey et al., 2017). The debate regarding confidence in the data obtained from such extraction-characterization strategies is still current due to the wellknown bias of the extraction step, which is never complete and may disrupt the native polymer organization. The general knowledge regarding flax plants, their developmental stages and bast fibre characteristics is well addressed (Goudenhooft et al., 2019a), but the impact of stress on the cell wall biochemistry or ultrastructure of other flax stem cell types is lacking. For instance, the stem epidermis covered by a cuticle, the cambial layer and the primary and secondary xylems have been less documented (Lion et al., 2017).

The analysis of the cell wall proteome has revealed the presence of a number of proteins known to be potentially involved or involved in plant cell wall metabolism.

Very little is known about structural proteins, and studies of parietal proteomes often show parietal proteins involved in wall metabolism. Indeed, structural proteins are difficult to extract by nature, making them difficult to purify from others and therefore to study. However, major achievements have been reported regarding flax protein expression (Corbin et al., 2013), as well as genome identification and evolution patterns of the main protein family according to differential regulation (Corbin et al., 2018).

Hydroxycinnamates are phenolic molecules. These phenolic compounds are most often esters linked to polysaccharides and esters or ethers linked to lignin monolignols. These compounds can act as interpolymer coupling agents, for example, between polysaccharides and lignin or polysaccharides and structural proteins containing tyrosine amino acids. Hydroxycinnamates, such as lignans, also play an important role in plant defence (Mnich et al., 2020). An attempt to identify and localize phenolic compounds in cell walls by microscopy was made using a laccase tagged with colloidal gold; this enzyme was able to bind to phenolic compounds (Gorshkova et al., 2000). The authors revealed several gold particle distribution patterns, with compact labelling in xylem and bast fibres; 
a large proportion of bast fibre wall phenolics consisted of phenolic acids rather than lignin. Lignin is often described as a 3D phenolic polymer (Liao et al., 2020). In flax, lignin is mainly concentrated in xylem, and the bast fibre is very poor. This polymer contributes to the mechanical properties of the supporting tissues, ensures the proper functioning of the xylem and participates in the defence of plants against pathogenic microbes. In addition to its protective role in plants, flax lignin may be of interest in biotechnology (Li et al., 2016). The spatial regulation of constitutive lignin under development or during stress is well documented (Le Roy et al., 2017). The xylem histological part of the stem was particularly well investigated with an elaborate chemistry strategy coupled with a creative microscopic investigation (Lion et al., 2017).

Flax polysaccharides arguably represent the main component of the stem in terms of the mass, with cellulose being the major component in shives (Beaugrand et al., 2014; Nuez et al., 2020) (xylem part) and in the bast fibres (Bourmaud et al., 2019).

Studying the variations in the wall composition according to tissues in situ, depending on the stage of the development of the organ or plant (or in response to stress), is a first step towards a better understanding of the relationships between the composition and function of walls in plants. Some biochemical compounds are naturally fluorescent, including aromatic substances or compounds containing conjugated double bonds, and this property can be used for detection via fluorescence imaging techniques. For example, lignins and hydroxycinnate exhibit intense fluorescence in the UV and visible regions. In proteins, the dominant fluorophore is the indole group of tryptophan, which absorbs near $280 \mathrm{~nm}$ and emits approximately $340 \mathrm{~nm}$. In particular, synchrotron radiation provides deep-UV illumination (DUV), enabling multipurpose molecular fluorescence identification (Giuliani et al., 2009). Using a synchrotron source, a spatial resolution compatible with the sizes of the cell and cell wall (10-50 $\mu \mathrm{m}$ and $1-5 \mu \mathrm{m}$, respectively) can be attained with a good signalto-noise ratio (Allouche et al., 2012). The excitation at $275 \mathrm{~nm}$ coupled with an emission in the range $327-353 \mathrm{~nm}$ makes it possible to visualize the proteins thanks to the natural fluorescence of tryptophan and tyrosine, which they harbour in their amino acid sequence (Jamme et al., 2014). Using the same excitation wavelength, phenolic compounds exhibit natural fluorescence and can be detected at the cell wall scale in lignocellulosic plants at an emission over $380 \mathrm{~nm}$ (Devaux et al., 2018a). Because of fluorescence emission bandpass filters, hydroxycinnamate acids can be partially distinguished from ligninpolymerized phenolic components. Indeed, fluorescence emission bandpass filters at 420- 
$460 \mathrm{~nm}$ and $480-550 \mathrm{~nm}$ can be used to highlight hydroxycinnamate acids and lignin differentially (Jamme et al., 2013).

Since polysaccharides are not autofluorescent, mid-infrared (FTIR) spectroscopy has been used to track polysaccharide compositions. Indeed, FTIR microspectroscopy has proven its value in monitoring hemicellulose metabolism in flax (Chabi et al., 2017). Additional work has highlighted the interest of this approach for flax, examining growth-induced modifications of cells (Stewart et al., 1995). In this study, Stewart et al. reported the spectra of bast fibre cell walls with a predominance of cellulose absorbance. In addition, this work suggested the presence of acetylated hemicelluloses (xylan and/or glucomannan).

In the current study, FTIR microspectroscopy was performed on only bast fibres. This choice is motivated by the economic interest of that fibre and because it is well documented in the literature in comparison to the others.

The purpose of this research is to monitor when, where and with what amplitude the biochemical components in flax varied using FTIR (bast fibre only) and deep UV fluorescence after a gravitropic event. Two conditions were chosen: i) during the normal growth of the flax plant as a control plant and ii) following severe stress, namely, $90^{\circ}$ bending, which generates gravitropism. These two growing conditions were combined with the three main stages of flax development, and for each, the proteins, hydroxycinnamate and lignin distributions and relative amounts were studied for the five stem cell types investigated.

\section{Material and methods}

\subsection{Flax stems, sampling protocol and growing conditions}

Flax plants (Linum Usitatssimun L., Bolchoï, seeds provided by Terre de Lin, France) were studied. Seeds were sown in pots and cultivated outdoors (Lorient, France) in 2017 at a conventional seeding rate (approximately 1800 seeds $/ \mathrm{m}^{2}$ ) (Bourmaud et al., 2016). The plant growth stages were estimated based on the average plant height, days after sowing and cumulative temperature (Goudenhooft et al., 2017).

A control (C) batch containing plants that never tilted was used as a reference. Three additional pots were used for the experiments, consisting of pots inclined at approximately $90^{\circ}$ at different key stages of plant development (Fig 1). The first pot was tilted at the beginning of the VS, when plants reached approximately $25 \mathrm{~cm}, 29$ days after sowing and a cumulative temperature of $370^{\circ} \mathrm{C}$. The second pot was inclined during the $\mathrm{FG}$ period, when plants were approximately $50 \mathrm{~cm}, 40$ days after sowing and $510^{\circ} \mathrm{C}$ of cumulated 
temperature. Finally, the third pot was tilted at plant maturity (M), in the present case when plants were approximately $80 \mathrm{~cm}, 77$ days after sowing and when the cumulative temperature reached the expected $1000^{\circ} \mathrm{C}$ (Goudenhooft et al., 2017).

At each stage of tilting, some plants were sampled from both the control and tilted pots 4 days later, as it is the time required by plants to return to the vertical station (Ibragimova et al., 2017). Sampling consisted of collecting $10 \mathrm{~cm}$ samples (starting from $2 \mathrm{~cm}$ above the cotyledons), which correspond to the lasting curvature zone when recovery takes place. Immediately after sampling, stem portions were fixed overnight in a solution of $4 \% \mathrm{v} / \mathrm{v}$ formaldehyde in $0.1 \mathrm{M}$ phosphate buffer $\left(\mathrm{pH} \mathrm{7.2)}\right.$ at $4^{\circ} \mathrm{C}$. Then, they were gradually dehydrated in a series of ethanol/distilled water solutions $(30 \%, 50 \%$ and $70 \% \mathrm{v} / \mathrm{v})$ and stored at $4^{\circ} \mathrm{C}$.

\subsection{Deep UV Fluorescence imaging at the SOLEIL synchrotron DISCO beamline}

The DISCO beamline and the imaging microscope setup have been fully described in Giuliani et al.(Giuliani et al., 2009) and in Jamme et al. (Jamme et al., 2013). The so-called TELEMOS microscope is a modified full-field microscope (Axio Observer Z1, Carl Zeiss $\mathrm{GmbH}$, Germany) coupled to the monochromatized synchrotron beam. The power delivered on the sample at the DISCO beamline imaging branch is limited to a few microwatts $(1.1 * 10-6 \mathrm{~W}$ at $280 \mathrm{~nm})$. This value avoids beam photodamage by deep UV absorption. The synchrotron beam aligned and focused on the sample using an Ultrafluar $40 x$ (NA 0.6) objective provides a field of view of $250 \star 250 \mu \mathrm{m}^{2}$ with a pixel size of $244 \mathrm{~nm}$. The microscope is equipped with a 16-bit back-illuminated CCD camera (Pixis BUV, Princeton Instrument, USA) that allows 65536 grey levels to code the fluorescence intensity and an image size of $1024 \times 1024$ pixels. The acquisition of images is driven by the ImageJ plugin $\mu$ Manager (Edelstein et al., 2010).

The excitation wavelength was set at $275 \mathrm{~nm}$. A dichroic mirror at $300 \mathrm{~nm}$ and three bandpass filters were used for the acquisition of multispectral images. The emission filter at 327-353 nm selected the fluorescence of tryptophan and tyrosine found in the proteins, and the emission filter at 420-460 nm made it possible to acquire images of phenolic compounds corresponding to both the hydroxycinnamic acids and lignin. The emission filter at 480-550 nm was retained as a more specific lignin (Frédéric et al., 2013). Image acquisition was performed at room temperature, and the acquisition time was set to $10 \mathrm{~s}$ for the three filters. Finally, visible images in transmission mode were acquired in the 
sequence of multispectral acquisition. The acquisition time was set to $100 \mathrm{~ms}$ for the transmission images.

The reference images for background and illumination heterogeneities were acquired once per day, and the run of the entire acquisition covered 3 days. The background images corresponded to the signal recorded by the camera without any illumination and any sample. Using the current camera, the background level was approximately 700 and depended on the filter, acquisition time and location in the image. One background image per bandpass filter was acquired by setting the acquisition time accordingly to $10 \mathrm{~s}$. The illumination field depends on the synchrotron beam alignment and the focal plane. The images of the illumination were acquired using a luminescent reference compound ( $\mathrm{Nd}$ YAG crystal) using only the dichroic mirror without any filter and setting the acquisition time to $250 \mathrm{~ms}$. A Z-stack of 101 images was acquired with a $2 \mu \mathrm{m}$ step between each image. Flax stem whole sections with a $45 \mu \mathrm{m}$ thickness were obtained using a HM650V vibratome (Microm International GmbH, Waldorf, Germany) and were deposited on a 1" diameter quartz coverslip (R525000, Esco Optics). Just before the acquisition, the sections were mounted in distilled water and sandwiched with a second circular quartz coverslip. A 10x (NA 0.2) Ultrafluar Zeiss (Carl Zeiss $\mathrm{GmbH}$, Germany) lens was used to provide a field of view of $1.116 \times 1.116 \mu \mathrm{m}^{2}$ with a pixel size of $1.092 \mu \mathrm{m}$. Stem sections were approximately 3-4 mm large, and a single image was not sufficient to observe the whole section. A series of images were acquired to cover the whole surface of the section after defining a region of interest in the centre of the images that corresponded to the region illuminated by the synchrotron beam. Depending on the section, between 20 and 30 individual images were acquired to scan the whole section.

\subsection{Fluorescence image preprocessing and analysis}

Fluorescence images were preprocessed in Devaux et al. (Devaux et al., 2018b) using the principles described in (Tomazevic et al., 2002) for shading correction. The goal was to remove the camera background and compensate for the illumination inhomogeneity using eq 1:

$\operatorname{IMC}(\lambda)=\frac{(\operatorname{IM}(\lambda)-\operatorname{BKG}(\lambda))}{\operatorname{ILL}(z)} \quad$ eq $(1)$

where $\operatorname{IM}(\lambda)$ is the raw image acquired using filter $\lambda, \operatorname{BKG}(\lambda)$ is the additive background, $\operatorname{ILL}(z)$ is the $z^{\text {th }}$ image of the illumination reference Z-stack and $\operatorname{IMC}(\lambda)$ is the preprocessed image. In the present work, the $z^{\text {th }}$ illumination image was obtained by 1 ) calculating an illumination image as the maximum intensity of all individual images of the section and 2) 
selecting the $z^{\text {th }}$ image $\operatorname{ILL}(z)$ in the illumination reference $Z$-stack as the most correlated to the estimated illumination image. The main steps of image preprocessing are illustrated in the Supplementary Data section.

Images of the whole section were finally built for the three emission filters by merging the preprocessed images into three mosaic images, called composite images, using the information provided by the moving stage. The intensities at the stitching interfaces were set to the maxima between the two adjacent individual images.

Fluorescence image analysis included image observation and fluorescence intensity measurement for each given cell type. False colour images were built from the three emission filters, as described in Table 1. In the resulting colour images, the regions rich in proteins are identified as mainly blue regions, the regions rich in hydroxycinnamates are identified as green regions, and the regions rich in lignin are identified with a colour varying between yellow and red (see Fig 2).

Fluorescence intensities were measured in the images for each filter by manually selecting pixels corresponding to different cell types: epidermis (ep), bast fibres (bf); cambium (ca), secondary xylem (xs) and primary xylem (xp). For each cell type, two sets of pixels were selected from each of the four quarters of the section. The intensities were averaged over pixels, resulting in 5 cell types $\times 4$ quarters $\times 2$ repetitions $\times 3$ filter measures per image. The intensities were compared using variance analysis by considering three experimental factors: development stage, tilting conditions, cell types and their interactions.

Image processing and variance analyses were performed using MATLAB 2019a with the commercial 'Statistics and Machine Learning' toolbox' (The MathWorks, France).

\subsection{Fourier transform infrared microspectroscopy - spectral analysis}

Small cylinders (approximately $5 \mathrm{~mm}$ in length) of flax stems from the 3 development stages (see section 2.1 and Fig 1), under normal conditions and under stress with a $90^{\circ}$ tilt, were embedded in paraffin (Automate Tissue Tek VIP 3000). Sixteen thick cross sections were obtained using an HM355S microtome from Microm and were collected on ZnS windows. The sections were submitted to a Histochoice clearing agent (Sigma H2779) solution to remove the paraffin.

Localized spectra were acquired by mid-infrared microspectroscopy using a Tensor 27 (Bruker Optics) spectrometer equipped with a Hyperion 2000 microscope (Bruker Optics). Visible images were obtained using a Sony camera (Exwave HAD, SSC-DC80P). A 36x objective was selected, and depending on the cell sizes and stage of development, an 
aperture of 400 to $1600 \mu \mathrm{m}^{2}$ was set. Infrared spectra were collected in the $4000-700 \mathrm{~cm}^{-1}$ range at a resolution of $8 \mathrm{~cm}^{-1}$. Each spectrum summed 700 scans for the background and 500 scans for the samples.

All spectra were baseline corrected and normalized using the acquisition software OPUS7.5 (Bruker optics). The spectra were cropped to the $2000-700 \mathrm{~cm}^{-1}$ range, highlighting the polysaccharide region of interest for the bast fibre components. Norris gap second-derivative spectra were assessed using Unscrambler software (version 10.1, Camo). The second-derivative spectra were thereafter multiplied by $(-1)$.

\section{Results and discussion}

3.1. Qualitative analysis of the fluorescence images according to development stages and tilting conditions

Fig 2 shows the fluorescence images of the flax stem cross sections at the young development stage for the control plant for the three filters 327-353 nm (Fig 2a), 420-460 $\mathrm{nm}$ (Fig 2b) and 480-550 nm (Fig 2c) corresponding to proteins, hydroxycinnamate and lignin, respectively, and the composite view (Fig $2 \mathrm{~d}$ ). One can visually observe that the intensities are different between channels and that the fluorescence signal seems uniform all around the section circumference. The protein fluorescence is mainly located in the secondary xylem. The hydroxycinnamate fluorescence is intense in the cambial tissue and more diffuse in the xylem areas (Fig 2b). The lignin fluorescence is stronger in the xylem area. The epidermis fluorescence is the most intense in the hydroxycinnamate (Fig $2 \mathrm{~b}$ ) and lignin (Fig 2c) channels, whereas only a slight signal is visible in the protein (Fig 2a) channels. Although we selected carefully bandpass filters to collect the fluorescence emission of the hydroxycinnamate and lignins separately, we cannot exclude a partial overlap of the emission spectra of these compounds, and caution should be taken when assigning the signals in absolute values. Finally, one can notice that in the inner part of the stem, the parenchymatic cells do not fluoresce much regardless of the channel used. The three images were combined to obtain a composite colour image that reveals the distribution of the three fluorescence signals (Fig $2 \mathrm{~d}$, composite). The proteins are identified in the blue channel, while the hydroxycinnamates are given by the green channel, and the lignin is depicted by the red channel (Fig 2e). The interpretation of the colours obtained is sometimes tricky and requires the quantification of the individual fluorescence intensity, which will be presented below. A quarter of the stem section was stained with phloroglucinol and zoomed in the picture $f$ (Fig 2f). One can follow from the outer part of the stem to the 
inward epidermis (ep). Then, the thick bast fibre wall is arranged in bundles (bf), followed by an area of several layers of small and active cells where the cambial area is located. Further on, we can see the xylem stained in red due to its high content of lignin, the xylem divided into (xs) as the youngest secondary xylem, and finally the oldest xylem as (xp) is the primary xylem build-up by the plant.

Fig 3 shows the composite fluorescence images of the flax stem cross sections using the same spatial scale for different maturity stages and the control versus $90^{\circ}$ tilted conditions obtained following the procedure illustrated in Fig 2.

\section{Evolution according to the development stage}

The first qualitative information is that during the development of the control plant (Fig 3 ac), a global intensity decrease is observed. The mature stage M_C (Fig $3 \mathrm{c}$ ) displays a lower fluorescence intensity, and the protein signal is almost extinct at this oldest stage. These observations also apply to bast fibres, with some traces of hydroxycinnamate and proteins at the MS. For FG and M stages, the protein signal is intense in the cambial area (Fig 3b) and in an active epithelium if any. The fluorescence intensity of the xylem area increases as the stem matures with a shift from blue green to green-yellow fluorescence. This shift is attributed to a decrease in proteins involved in cell wall metabolism as the stem ages (Fig 3c). The outer xylem part, located close to the cambium, always shows more intense fluorescence. The inner region of xylem shows green-yellow fluorescence, corresponding to the hydroxycinnamates and lignin channels, regardless of the considered developmental stage. Previous work has shown that during the starting stage of lignification, the structure of lignins can evolve; for herbaceous plants such as flax, lignin mainly originates from the polymerization of trans-para-coumaryl alcohol (Day, 2004). Lignins can also be linked to cell wall proteins (Monties, 1989) and to phenolics, ferulic or p-coumaric acids (Scalbert et al., 1985) (Monties, 1989). Thus, during the implementation of lignin, its structure can take different configurations related to the different fluorescence responses.

\section{Evolution related to the tilted effect}

For the $90^{\circ}$ tilted plant, the evolution is not as linear as that during the development stage. VS_90 presented more green fluorescence than FG_90 and M_90. More blue fluorescence is seen in FG_90 than in the two other stages. When the gravitropic response takes place during the VS, the cambial region is more intense than the control (see Fig 3a\&d), suggesting greater cambial activity with tilting. In the VS, the main difference is a more 
intense green ring visible in the innermost stem tissue, corresponding to the primary xylem. One hypothesis to explain this modification could be a consequence of a modification of the transport in the plant, probably of the sap after the curving of the stem, which could induce a mobilization or translocation of hydroxycinnamates. It is generally admitted that primary metabolic activity is reflected by the presence of proteins (Buchanan B., 2002). These proteins are cell effectors, structural proteins, etc. involved in the major processes of living organisms and cells. Arguably, hydroxycinnamate is a secondary metabolite. Their localization and modifications therefore reflect metabolic activity but are not as strong as the primary metabolism of proteins.

The restoration of the plant vertical position also occurred in the FG period (Fig 3 b\&e). During this step, the cambial region of tilted samples (Fig $3 e$ ) also seemed to be more fluorescent than the control samples (Fig 3. d). The protein signal areas and intensities (blue) were more pronounced, with the bast fibres being greener fluorescent (hydroxycinnamate) than the control plants.

When the gravitropic reaction occurs (Fig $3 \mathrm{c \& f}$ ), a much higher fluorescence intensity was observed at M_90 than at the control M_C. Despite the presence of well-mature cell walls, especially in the primary tissues, the cambial activity of tilted plants (Fig 3f) was still present but more limited than that of tilted plants at the younger stages, as shown by the reduction in the blue xylem "ring" in contact with the cambium (Fig $3 \mathrm{~d} \&$ ). Moreover, the area and intensities of the signals coming from hydroxycinnamates are much greater than those from any other samples, proving that mature cells are still able to react to inclination. This reaction most likely affects the lignification process or lignin cellular types such as xylem and hydroxycinnamate, which are precursors of this cell wall component.

It seems by eye that mature fibres are not strongly involved in the gravitropic reaction, whereas the xylem secondary part is. In addition, regarding the bast fibre, the signal intensities of M_90 seemed lower than those of tilted plants from previous growth stages and were similar to those of the control M_C plants.

Finally, no polarisation of the signal in response to tilting is analysed 'by eye' observation. This comment is mandatory because a polar gravitropic response is possible, visible at the scale of the stem between the opposite and bending sides (Ibragimova et al., 2017). Indeed, it has been reported that some morphological modifications in response to gravitropism can take place in the bast fibre but only when bending takes place at a juvenile plant stage. 
This qualitative observation of the signals by eye offers information, but quantitative information would provide more information. Therefore, we measured the fluorescence intensity on the cross sections, as explained later.

\subsection{Fluorescence quantitative analysis according to the development stages and tilting conditions}

For a quantitative fluorescence analysis, an arbitrary virtual division of the stem section into four quarters, called 1 to 4 , was performed, as illustrated in Fig $4 \mathrm{~A}$. The fluorescence intensity collected for each filter allows quantitative evaluations in the fluorescence count unit.

The fluorescence intensity around the stem section was examined for the 5 cell types including the epidermis (ep), the bast fibre (bf), the cambium (ca), the primary (px) or the secondary (sx) xylem shown in Fig 2f. The specific cell type intensity measurements were obtained by manual selection of the pixels (Fig 4B). The fluorescence intensity of the cell types was measured for the three filters as the average intensity of the selected pixels. This measurement was repeated for each of the 4 quarters of the stem.

From those average fluorescence intensity values, an analysis of variance (ANOVA) was performed for each filter (Fig 5). The developmental stage, tilting, cell types and all interactions were found to be significant. Because proteins, hydroxycinnamates and lignin arguably do not fluoresce in the same manner and in the same environment, a higher fluorescence does not necessarily mean higher molar amounts; therefore, it is not possible to compare the different components as molar amounts based on their respective signals. If we focus first on the development stage effect, then the average fluorescence intensity for the three emission channels corresponding to proteins (Fig 5a), hydroxycinnamates (Fig $5 b$ ) and lignin (Fig $5 \mathrm{c}$ ) varied between the 3 development stages. The highest intensity for proteins and hydroxycinnamates was observed in the fast growing stage for both the control and $90^{\circ}$ tilted stems (FS_C or FS_90), and the lowest intensity was observed in the vegetative stage (VS_C or VS_90 ${ }^{\circ}$ ). This trend is different for lignin: an increase in the intensity occurred between stages VS and FG before reaching a plateau. In contrast, the lignin fluorescence seemed equal for the three developmental stages of the $90^{\circ}$ tilted stems. If we focus now on the tilt effect, then the gravitropic response systematically induced an increase in the fluorescence intensity in the three channels compared to the control plant stems, by 51,28 and $23 \%$ for proteins, hydroxycinnamate and lignin, respectively. The $90^{\circ}$ tilt gives rise to an average increase of $32 \%$ of the fluorescence (Fig 
5), somehow confirming the qualitative observation (section 3.1, Fig 2). This result suggests a global boost in plant metabolism following lodging stress.

\subsubsection{At the cell type scale, evolution according to development stage}

To go further in the analysis, we looked at the fluorescence intensity according to the cell types. Fig 6 presents the average fluorescence intensity for the 5 cell types related to their developmental stage and tilt condition. The epidermal protein intensity signal was weak and did not change according to the VS and the FG and M stages of the control plants (Fig 6). The hydroxycinnamate fluorescence signal is more intense and remains stable. The highest fluorescence intensity was measured for lignin, but the standard deviation of the average values was so large that no significant trend could be deduced. Here, the very thin layer of the epidermis is arguably a technical limitation with respect to the pixel resolution, which might explain in part the importance of the standard deviation (SD) observed.

Bast fibres are thicker, and the SDs are very small regardless of the constituent under consideration (Fig 6, second line of histogram). The intensity of protein fluorescence increased between the VS and $F G$ stage and then decreased between the $F G$ and $M$ stages in the control plants. The intensity of the hydroxycinnamate fluorescence remained almost unchanged between the VS and FG stage and then decreased at the M stage. The lignin signal evolves accordingly, with only a decrease at stage M. Scarce literature deals with the quantification or localization of lignin in bast fibres, and a recent report based on safranin ratiometric image investigations on flax stem cross sections has presented a slight increase in the lignin content of mutant plants during cell development (Baldacci-Cresp et al., 2020).

Due to the economic importance of flax bast fibres, more literature is available regarding their composition (Akin, 2013; Bourmaud et al., 2018; Bourmaud et al., 2019) and evolution during plant growth and in response to stress (Goudenhooft et al., 2019a). In connection with Fig 3, the colour of the bast fibre evolves with maturity; in the FG stage, the blue colour representing mainly proteins is evident with a homogenous colour within the fibre cell wall, indicating probably the achievement of the transformation of the immature Gn wall into the mature $G$ at this stage (Gorshkova et al., 2015). This qualitative observation is supported by the protein fluorescence peak observed in Fig 6 (see FG-C, 'Bast Fibre Proteins'). The structure of bast fibres has been demonstrated to be progressive, with a first $\mathrm{Gn}$ layer composed of cellulose and long galactan chains evolving towards a more structured $G$ layer. In this new and mature layer, the length of galactan chains is reduced under the 
action of galactosidase enzymes, inducing their entrapment between cellulose microfibrils (Gorshkova et al., 2015) and a more cohesive and stiff (Arnould et al., 2017) structure. By homology with cell wall remodelling in a grape cell wall, during development, an increase in the abundance of structural proteins, extensin and arabinogalactan-protein (AGP), which correlates with cell expansion events, was reported. Here, such protein family identification is not possible since we indifferently detected all tryptophan that belongs to the whole protein class. However, an increase in AGP and extensin during flax fibre development is more likely (Day et al., 2013).

The cambium fluorescence signals (third line of histogram, Fig 6) for proteins, hydroxycinnamates and lignin show similar trends to the bast fibre, i.e., an increase between the VS and FG stage, followed by a slight decrease in the M stage. The fluorescence intensity in cambium is rather high, and the variations between developmental stages are marked.

The secondary xylem (xs) cells demark with the other cell wall types. Indeed, for fluorescence signals attributed to hydroxycinnamates or lignin, there was a significant decrease from the VS to the M stage. The protein fluorescence is higher than that of the other cell types, and signals for proteins fall drastically between the FG and M stages. In contrast, for the signals attributed to hydroxycinnamates and lignins, the decrease is progressive between the VG and $M$ stages. Regarding lignin, a recent report using an elegant tag of lignin specifies the active areas of lignification in the secondary xylem of flax (Lion et al., 2017). The authors showed temporal lignification differences among the xylem vessel, ray parenchyma cells and tracheid cells, as well as revealing the polarization at the scale of a single-cell lignification dynamics. In this work, such resolutions could not be achieved, but we observed a slight decline in the fluorescence intensity in stages $F G$ and M compared to the VS (Fig 6).

Finally, the xylem primary cell walls seem to display a unique dynamic over developmental stages, as no significant variations could be detected from the VS to the $M$ stage, regardless of the three biochemical components targeted (Fig 6).

\subsubsection{At the scale of the cellular type, evolution according to the $90^{\circ}$ tilt stress}

The epidermis (ep) fluorescence signals of the proteins, hydroxycinnamates and lignin did not seem to change in stems after $90^{\circ}$ tilt stress (Fig 6). The gravitropic response may also be difficult to detect in this thin layer due to an important SD that could mask a moderate physiological plant response. 
For the cambial area, all 3 biochemical families exhibited a stronger intensity after tilt, regardless of the maturity stage considered. This finding highlighted the impact of gravitropism on the cambial response and the preponderant function of this tissue in the plant reaction.

The xylem secondary cell wall type is affected by the gravitropic response that follows the $90^{\circ}$ tilt (Fig 6). Regarding the protein signal intensities. Indeed, the intensities in FG and M stages were significantly higher than those in the controls. The hydroxycinnamate signals were more intense in the VS and the $F G$ and $M$ stages than in the control stems. The lignin signal follows the same trend but with a smaller contrast between controlled and tilted plants.

The xylem primary cell wall type revealed only an increase in the protein signal at the FG stage. In contrast, for hydroxycinnamate, the FG stage is the only stage unaffected by the $90^{\circ}$ tilt stress. Compared to control stems, the lignin signal was higher in both the VS and the M stage, but the FG stage was unaltered.

Finally, the bast fibre after $90^{\circ}$ tilt could be expected to be involved in the response of the plant. Tilting is known to disrupt normal fibre thickening and lignification in tension wood fibre walls (Ghislain and Clair, 2017). Here, the fluorescence intensity recorded for proteins does not support a modification of the protein within the cell wall if tilt occurs in the VS or FG stage. The protein signals were unchanged between the control and tilted plants, in accordance with both our visual observations (Fig 3 ) and with the findings of Goudenhooft et al. (Goudenhooft et al., 2018). However, a slight protein signal increase was observed if tilt occurred in the $M$ stage. Tilting induces an increase in the hydroxycinnamate signal, and the highest difference between tilting and control plants was observed during the FG stage. For lignin, all tilted plants harbour a slight increase in the fluorescence compared to the control plant, and lignin is a well-known polymer involved in plant stress mechanisms.

\subsection{FTIR on the bast fibre}

To supplement the deep UV fluorescence examination of the 5 cell types, a study was performed by FTIR microspectroscopy to investigate the polysaccharide composition; this method has been successfully performed on wood fibres (Gierlinger et al., 2008) and flax mutant plants (Dymińska et al., 2014). We focused on the most targeted cell type of the flax stems in the literature, namely, the bast fibres.

FTIR and the development effect on bast fibre

A micro-FTIR investigation was performed on the bast fibre cellular type. 
Fig 7A illustrates the location of micro-FTIR spectra in a flax stem section. An average spectrum was calculated, and the assignment of the main absorption bands to biochemical compounds is presented in Fig 7B. The main mass at $1200-700 \mathrm{~cm}^{-1}$ is assigned to polysaccharides, such as cellulose, and heteropolysaccharides, such as hemicelluloses and pectin (Table 2). The band at approximately $1460 \mathrm{~cm}^{-1}$ is assigned to the $\mathrm{CH}_{2}$ bending of lipids when associated with the $\mathrm{C}-\mathrm{H}_{2}$ stretching bands at approximately 2850 and 2920 $\mathrm{cm}^{-1}$ (not shown). The bands at 1735 and $1245 \mathrm{~cm}^{-1}$ correspond to esters, while the absorption bands at approximately 1640 and $1540 \mathrm{~cm}^{-1}$ are signatures of the presence of proteins. The $1640 \mathrm{~cm}^{-1}$ band also refers to fibre internal water. The second-derivative spectra were processed to increase spectral differences in the $1800-700 \mathrm{~cm}^{-1}$ region (Fig 8). Cellulose, the major constituent of flax fibres, is identified by the spectral bands at 898 , 995, 1010, 1030, 1060, 1105 and $1160 \mathrm{~cm}^{-1}$ (Maréchal and Chanzy, 2000). The hemicelluloses, O-acetylated glucomannan, xylan and xyloglucan are also present in flax fibre absorbed in the same spectral region as cellulose but can be revealed by the shoulder at approximately 940 and $815 \mathrm{~cm}^{-1}$ (Himmelsbach et al., 1998).

The youngest development stage (Fig 8) differs from the later stages by bands assigned to lipids $\left(1735\right.$ and $\left.1460 \mathrm{~cm}^{-1}\right)$ and adsorbed water $\left(1640 \mathrm{~cm}^{-1}\right)$. The peak at $1010 \mathrm{~cm}^{-1}$ is associated with two shoulders at approximately 1600 and $1430 \mathrm{~cm}^{-1}$, assigned to carboxylate symmetric and antisymmetric COO- bands, which correspond to residual pectin. Its methylated or acetylated form is also present by bands at 1735 and $1245 \mathrm{~cm}^{-1}$. The variation in band intensities assigned to cellulose and hemicelluloses at 1010 and 1050 $\mathrm{cm}^{-1}$ mainly arises from the change in the pectins/cellulose or cellulose conformation ratio. Regarding the non-cellulosic polysaccharides, pectic galactan, as well as their processing enzymatic machinery (Goubet and Morvan, 1993), are known to be part of the bast fibre and evolve according to cell wall modelling (Mikshina et al., 2012), while galactan-protein plays a tremendous role with cellulose within $\mathrm{Gn}$ to $\mathrm{G}$ development (Girault et al., 1996).

FTIR and tilt effect on the bast fibre

When comparing FTIR signals from the control bast fibre and after tilting (Fig 9), the spectra of the youngest VS bast fibre from $90^{\circ}$ tilted plants presented absorption bands from 1105$1050 \mathrm{~cm}^{-1}$ with a higher intensity (Fig 9A). This result suggests an increase in the cellulose and hemicellulose contents for the bast fibre of tilted plants. Comparable trends have already been reported with some genetically modified flax lines, with modification of the cellulose ultrastructure and allomorphs in particular (Dymińska et al., 2014). For the FG stage, only slight differences were observed between the control and the $90^{\circ}$ tilted plant 
fibres, corresponding to variations in the absorbance intensity bands assigned to cellulose and hemicelluloses (995, 1030, 1050 and $1060 \mathrm{~cm}^{-1}$ ) (Fig 9B). At the MS, most of the signals of the $90^{\circ}$ tilted FG spectra are close to those obtained for control plants (Fig 9C), but the two bands drastically differ at 1105 and $1050 \mathrm{~cm}^{-1}$, indicating that there is also a change in cellulose and a broader panel of polysaccharides between these two conditions.

3.4 Seeking a stem polar effect on bast fibres by quantitative analysis of the fluorescence

To confirm the qualitative conclusion of the absence of polarity between the stem sides (Fig 3), we quantified the fluorescence according to the localization of the pixel selection in the whole circumference of the stem, with a more continuous position resolution (Fig 10). For that purpose, in the stem sections of control (M_C) and tilted plants (M_90), we measured the fluorescence from an initial ' 0 ' point arbitrarily located. Then, we performed a full walk on bast fibres where pixels were selected at different positions all around the stem circumference (Fig 10 a), with at least one set of measurements every $30^{\circ}$. No significant variations in any of the three channel fluorescence intensities can be observed, as seen in the average value linearized according to the angle of measurement (Fig $10 \mathrm{c}$ ). Indeed, although an up and down trend can be observed for each of the fluorescence channels, there is no trend for a higher or upper side of the stem with more proteins, hydrocycinnamates or lignins. The tilted stem section showed the highest fluorescence intensity, confirming the quantification of the bast fibre in Fig 6 and the ANOVA (Fig 5). Under our experimental conditions, the $10 \mathrm{~cm}$ stem samples collected (starting from $2 \mathrm{~cm}$ above the cotyledons), which correspond to the lasting curvature zone when recovery takes place. A comparison with side effects reported in the bast fibre shows an induced morphological change on the bast fibre on the pulling stem side compared to the opposite stem side and control plants, and only if the tilt was at the stage of the G-layer deposition (middle and lower part of stem) (Ibragimova et al., 2017). We hypothesize that this effect is not observed in our report because we may not have sampled the same stem section; for instance, $10 \mathrm{~cm}$ long samples were taken $2 \mathrm{~cm}$ after the cotyledon versus sampling 1 $\mathrm{cm}$ after the cotyledon (Ibragimova et al., 2017). In other words, we may have bypassed the area where this polarity occurred, probably by sampling slightly too far in the stem, even if the stem sampling area was slightly curved.

\section{Conclusion}


The aim of this work was to gain new insights into the dynamics of the cell wall composition in the different cell types of the flax stem during plant development and after $90^{\circ}$ tilt bending stress. The autofluorescence properties of proteins and phenolic compounds when excited at a deep UV (DUV) wavelength accessible to the SOLEIL synchrotron and multichannel fluorescence imaging have made it possible to track these compounds individually. The main output is that there are higher fluorescence signals of the hydroxycinnamate and lignin proteins at the FG stage for the five cell types of the stems, without exception. The fluorescence intensities decrease at the $M$ stage.

After a $90^{\circ}$ tilt of the flax stem, generally, the fluorescence intensity was higher in all five cell types. This molecular investigation shows that full histological flax stem organization is involved in the gravitropic response following tilting. Our data support the fact that the gravitropic response is also dependent on the metabolic activity of the plant, and the variations in proteins, hydroxycinnamates and lignin are influenced by the developmental stage when tilt occurs.

For cambium as well as the secondary xylem, the active cells are strongly affected by tilting, as demonstrated by a strong increase in the fluorescence intensity. In addition, if the gravitropic reaction occurs at plant maturity, cambial overactivity in tilted plants is still present but is moderate compared to reactions occurring at vegetative or maturity stages. The bast fibres were proven to also react after the stem tilt but moderately at the mature plant stage. No evidence of stem polarity generated after tilt was demonstrated by synchrotron DUV fluorescence imaging of the bast fibres, regardless of the developmental stage examined.

\section{Acknowledgements}

The authors are grateful to Marc Lahaye and Kevin Vidot for fruitful discussions. The authors acknowledge the financial support from SOLEIL for VV, CD and FC regarding Proposal 20171187. The authors also thank the French national research Network GDR 3710 INRAE/CNRS SYMBIOSE - Synthons et matériaux biosourcés for its support and the ANS $\mu$ Reshape' funding support received from the TRANSFORM department of INRAE. This research was also funded by the INTERREG VA FCE Program, FLOWER project, Grant Number 23. 


\section{Figures}

Figure 1. Scheme of the different steps of the experiment. The top part: a) Schematic representation of the flax stems at different maturity stages. The pots were never inclined and so acted as control $(C C)$ conditions, whereas other pots were tilted for 4 days. Tilting ( 90 ) was performed at three major stages of plant development (VS, FG and M), and tilted samples were collected 4 days after tilting, as depicted in the lower part b). Overall, 6 flax stem conditions were explored (VS_C, VS_90, FG_C, FG_90, M_C and M_90).

\section{a Development stages}
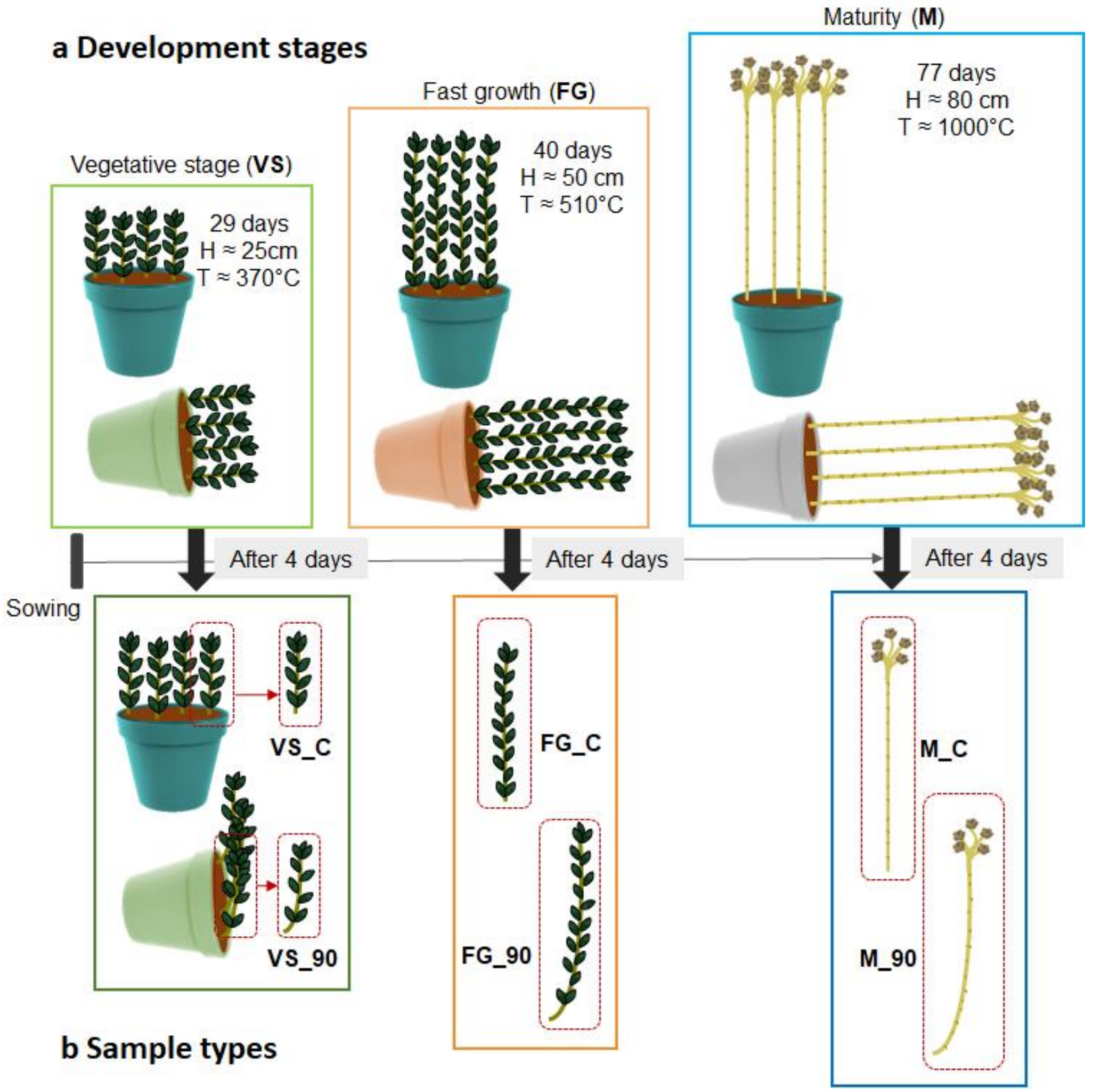
Figure 2 Individual channel fluorescence and composite view of the VS_C flax stem cross section. a) Fluorescence intensity of the channel of proteins, b) channel of hydroxycinnamate in c) channel of lignin, d) the composite view with the merged a-c channels, in e) a guide to interpret colours and in f) a phloroglucinol staining of the quarter of the stem section to present the 5 cellular components of this study. The field of view is $2.7 \times 2.5 \mathrm{~mm}^{2}$ for images a to $\mathrm{d}$. In $\mathrm{f}$, the inner stem part to the epidermis is (ep), the bast fibre (bf), the cambium (ca), the xylem - secondary (xs) and the xylem - primary (xp).

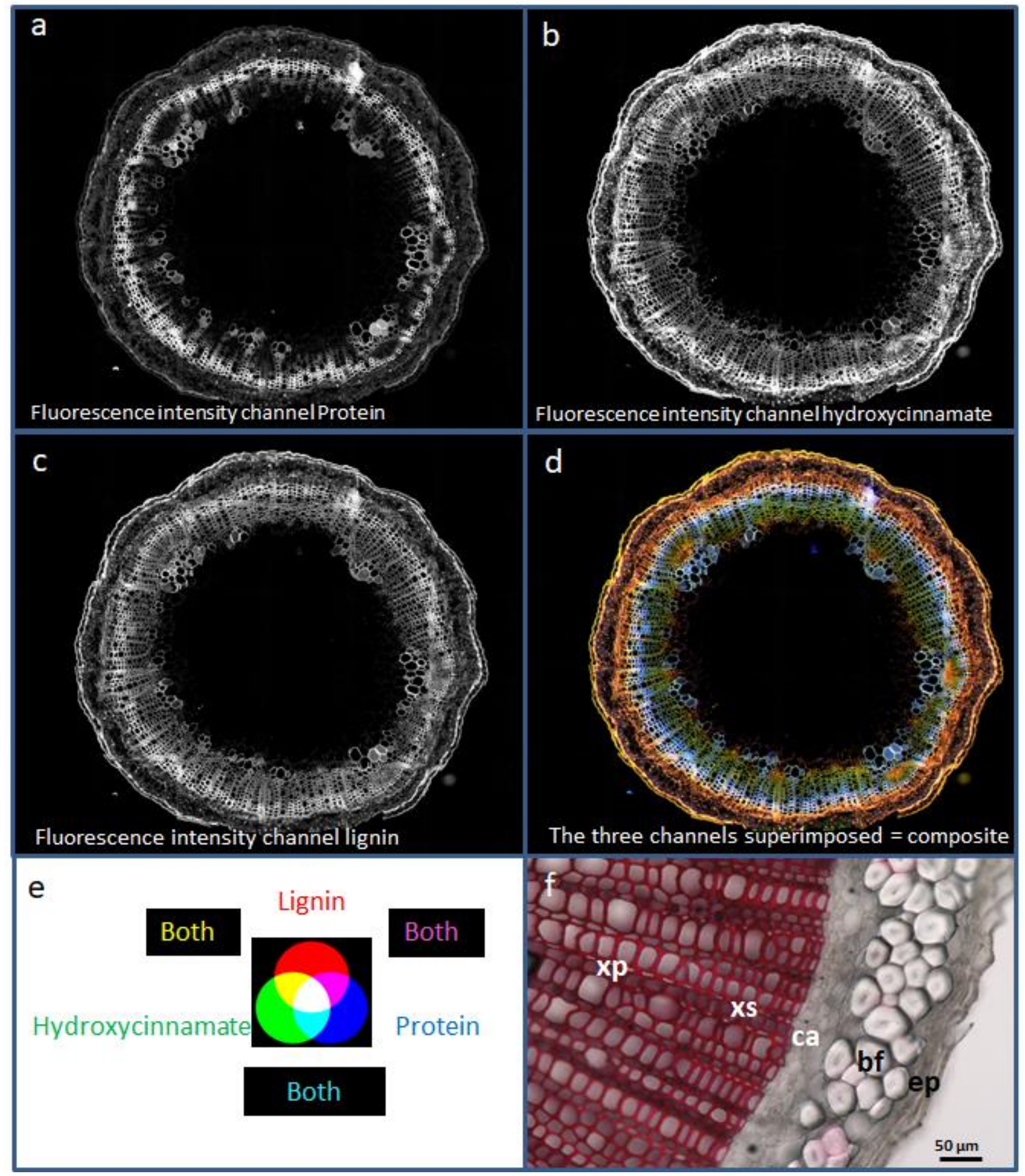


Figure 3. Composite fluorescence images of the control plants _ $C$ or tilted plants _ 90 , magnification 10x. Stem cross section from a control plant (a) and from a tilted plant (d) during the vegetative stage VS. Stem cross section from control (b) and tilted (e) plants during fast growth $F G$. Stem cross section of mature $M$ plants and control (c) and tilted (f) plants. In b, a caudal pod is visible on the left side of the stem.

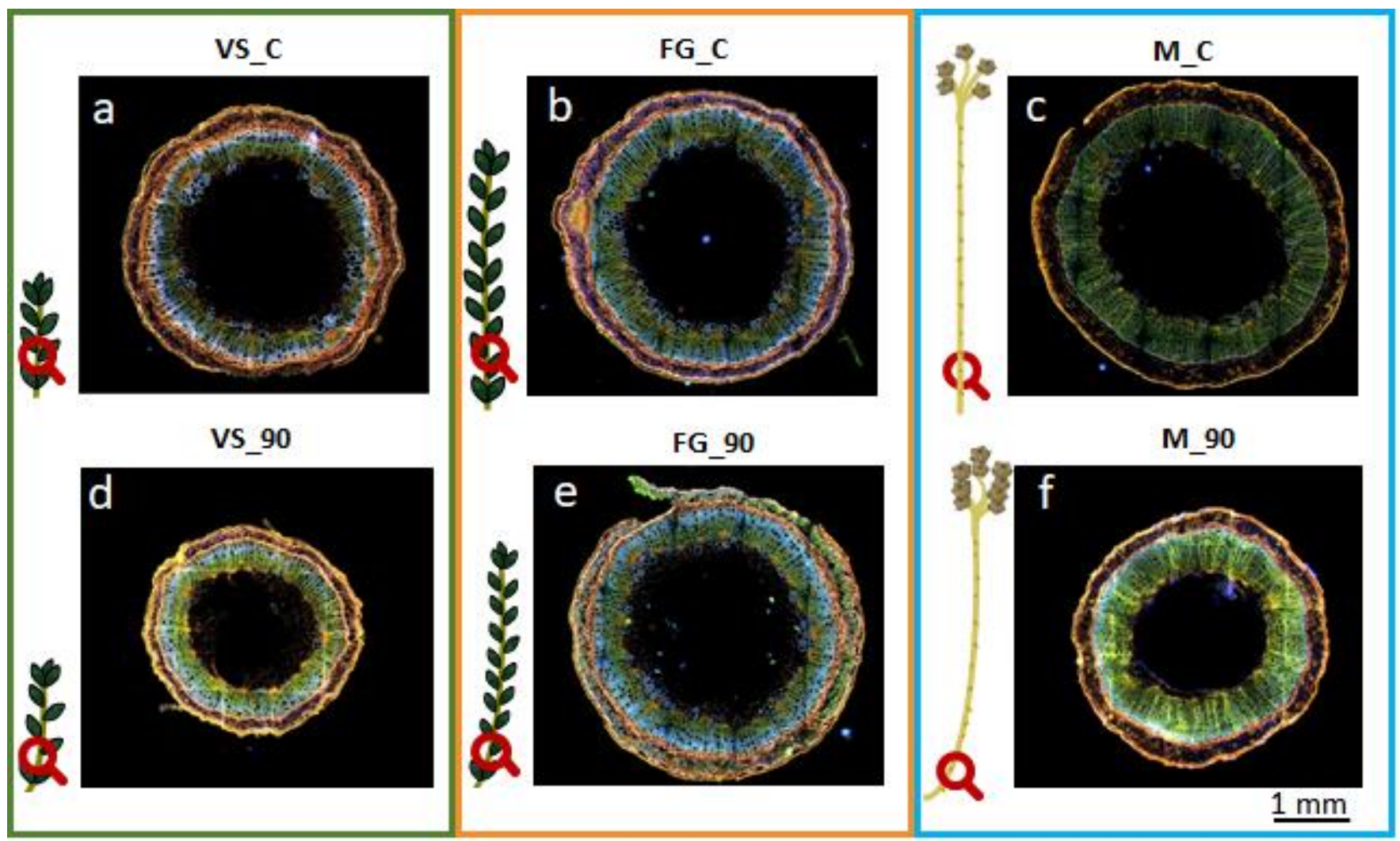


Figure 4 Fluorescence measurement in the cell types. A is the full stem section with the 4 sampling areas (labelled 1, 2, 3 and 4). The different cell types selected for fluorescence intensity quantification are indicated. B focuses on area 1 to illustrate the manual selection of pixels in the different cell types; the red lines go from the outer part to the inner stem part to the epidermis (ep), the bast fibre (bf), the cambium (ca), the xylem - secondary (xs) and the xylem - primary (xp). A zoom is provided for each vignette.

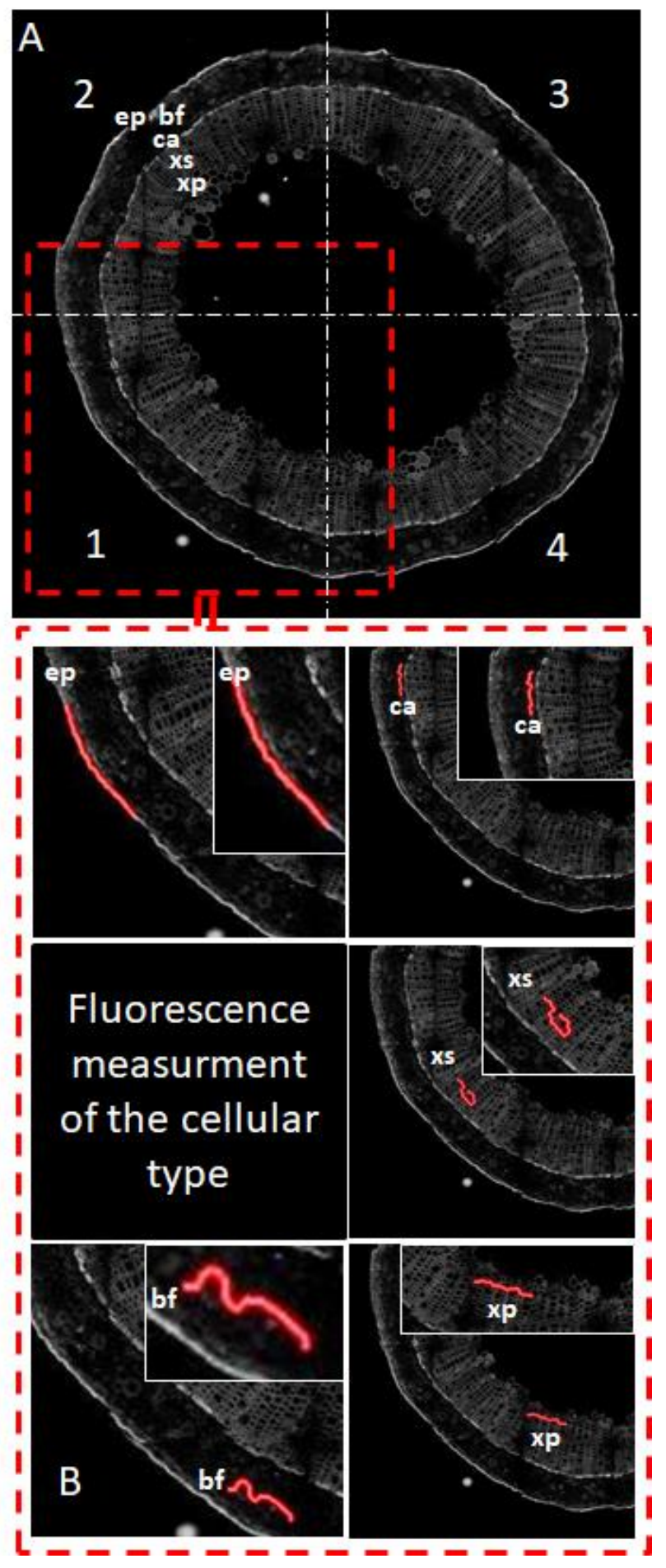


Figure 5 Average values of the fluorescence intensity (in arbitrary units) obtained from the ANOVA development stages $\times$ conditions.

Proteins (Filter 327-353 nm)

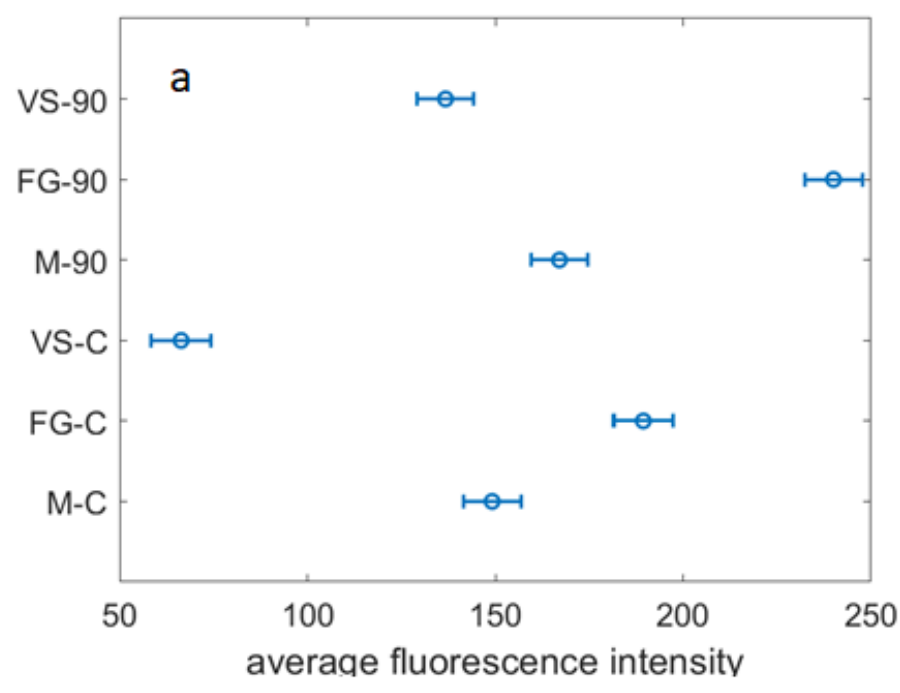

Hydroxycinnamates (Filter 420-460 nm)

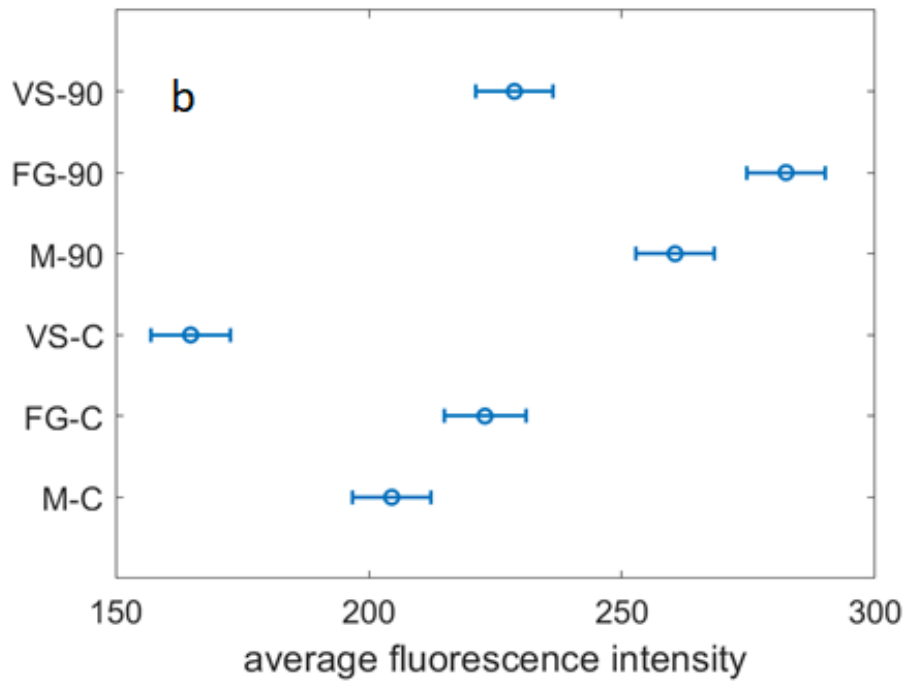

Lignin (Filter $480-550 \mathrm{~nm}$ )

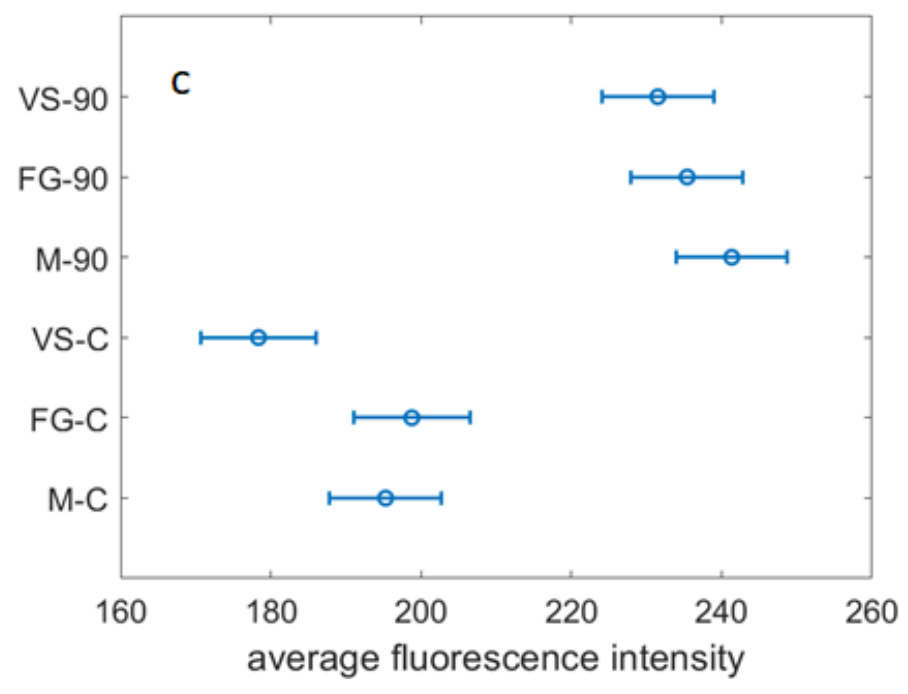


Figure 6 Cellular type average fluorescence intensity according to development and tilting conditions.
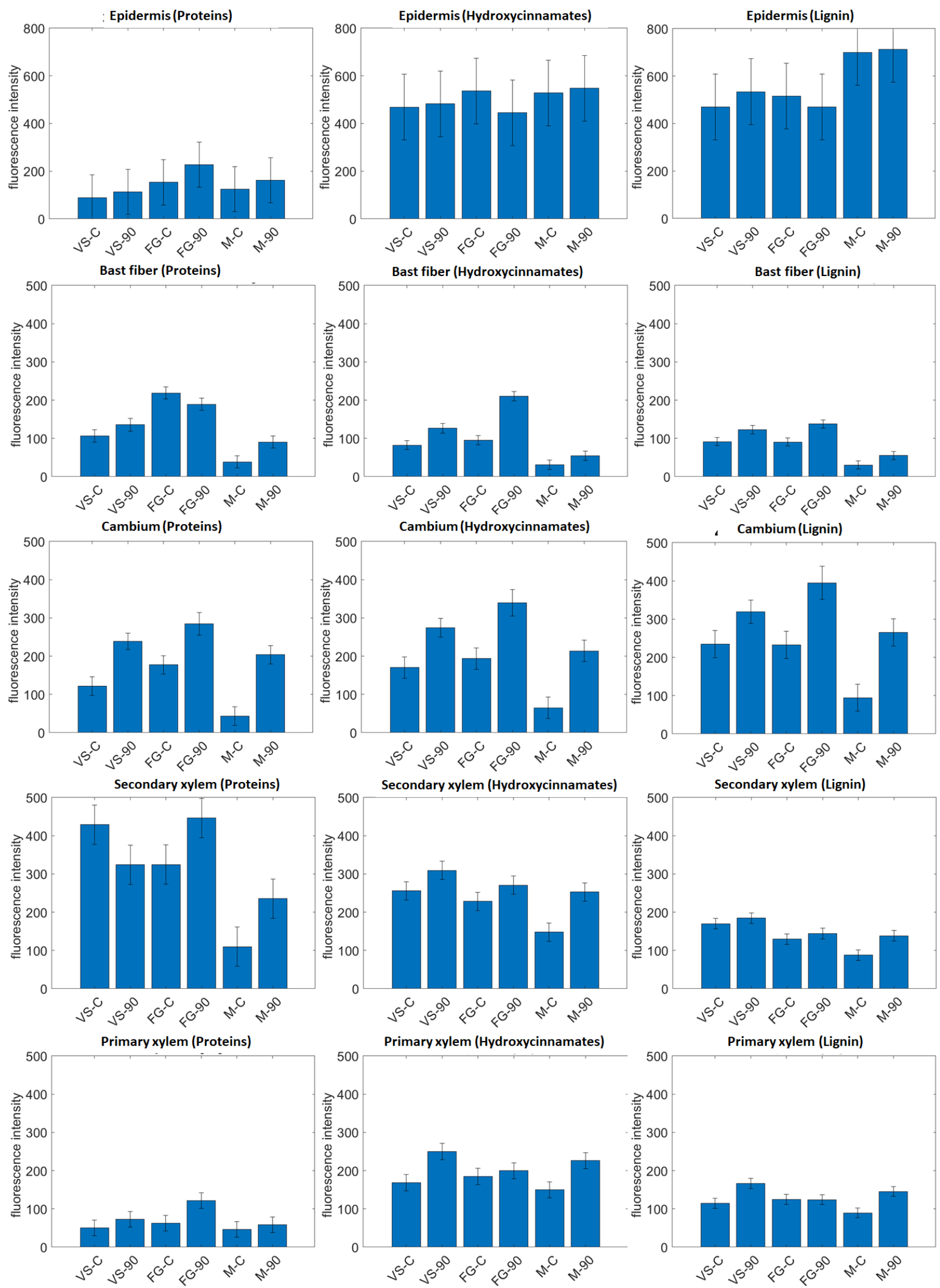
Figure 7. FTIR spectrum of bast fibres.

In a), the blue dots indicate the location of the bast fibre local spectra collected around the flax stem samples. In b), the absorption bands for the main components in bast fibre are indicated.
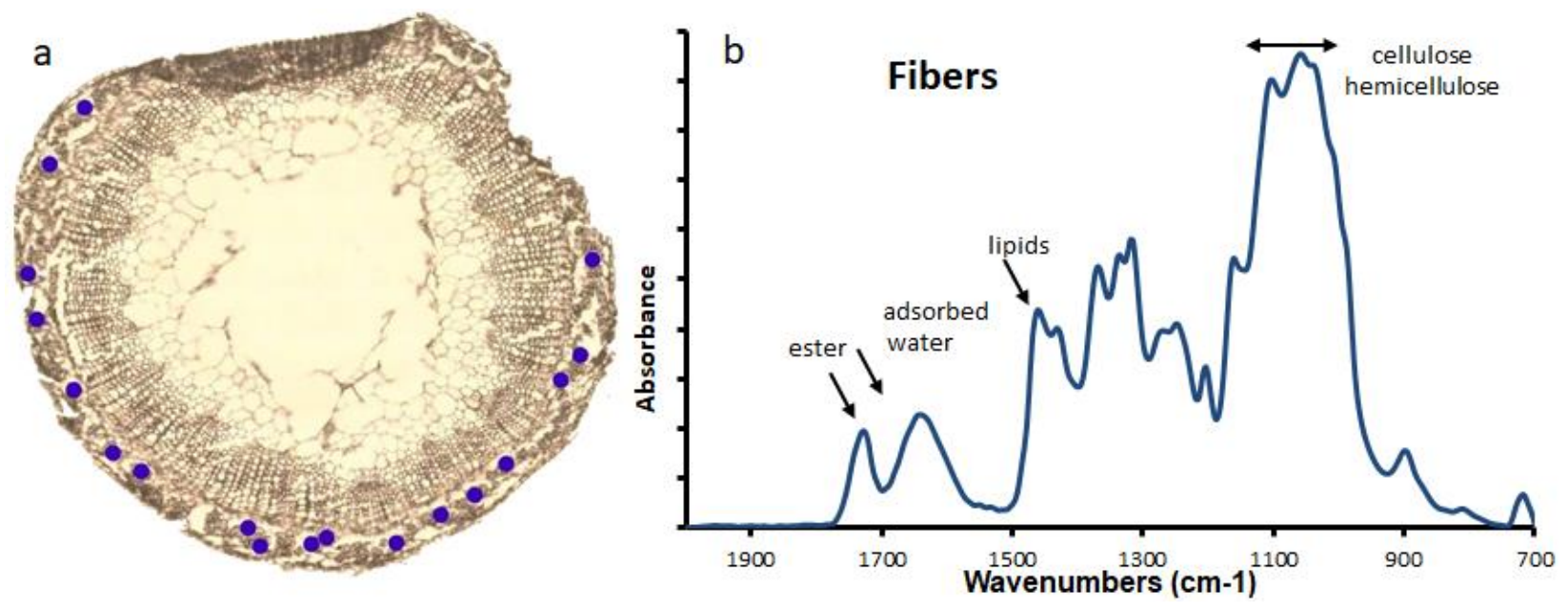
Figure 8

Effect of the development stage. The bast fibre second-derivative micro-FTIR spectral signals of control plants are superimposed. Red arrows indicate the bands of interest for the study.

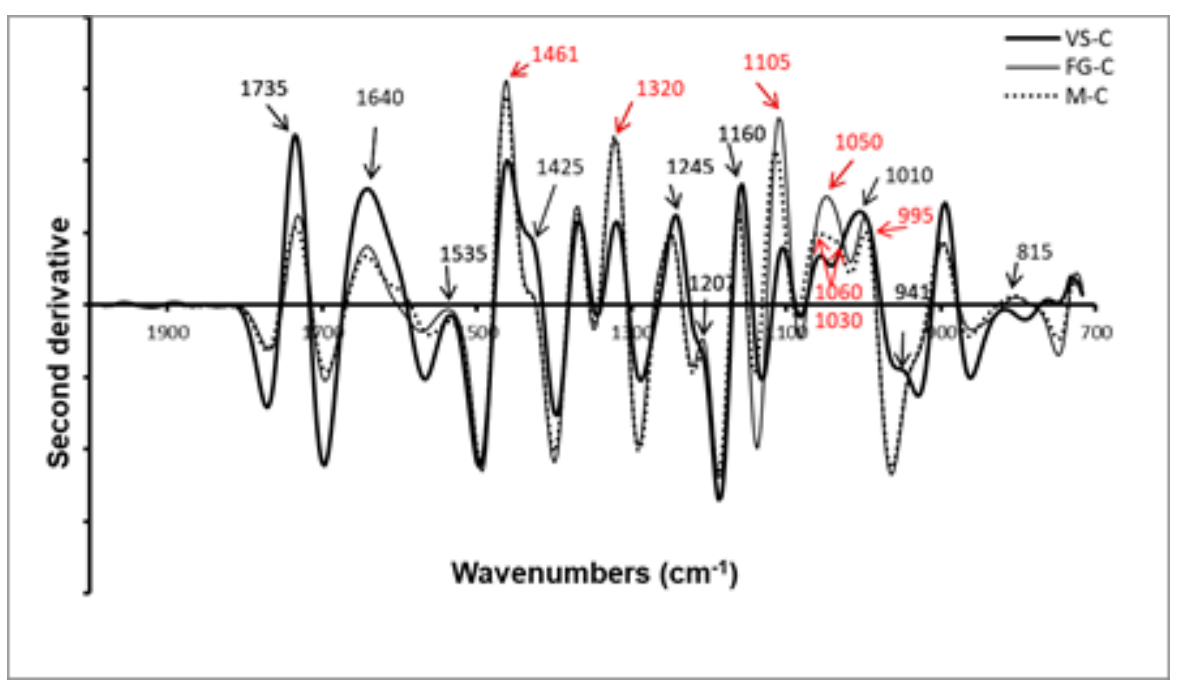


Figure 9 Effect of a $90^{\circ}$ tilt on the second-derivative micro-FTIR spectra of the flax bast fibre. Red arrows indicate the bands of interest for the study.

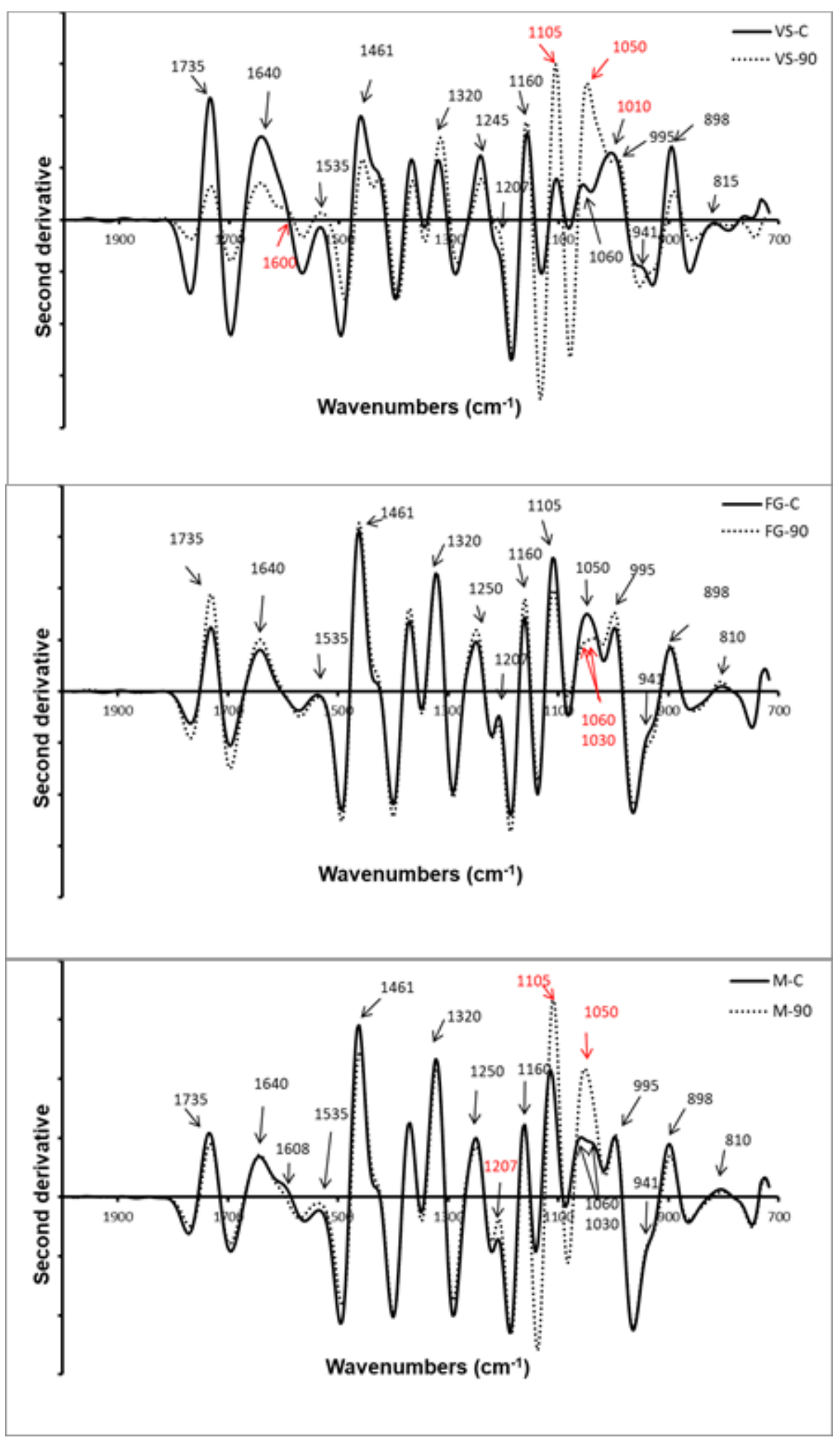


Figure 10 Investigation of the putative polarity in the stem by exploring the fluorescence of control versus tilted stems in bast fibres. Fig 10a) shows the arbitrary positioning of the fluorescence measurements around the stem section. Fig 10b) shows the location of the pixel fluorescence measurement in the bast fibre for M_C (square) and M_90 (lozenge). Fig 10c) shows the fluorescence intensity measured and expressed linearly for the tilted/untreated plants.

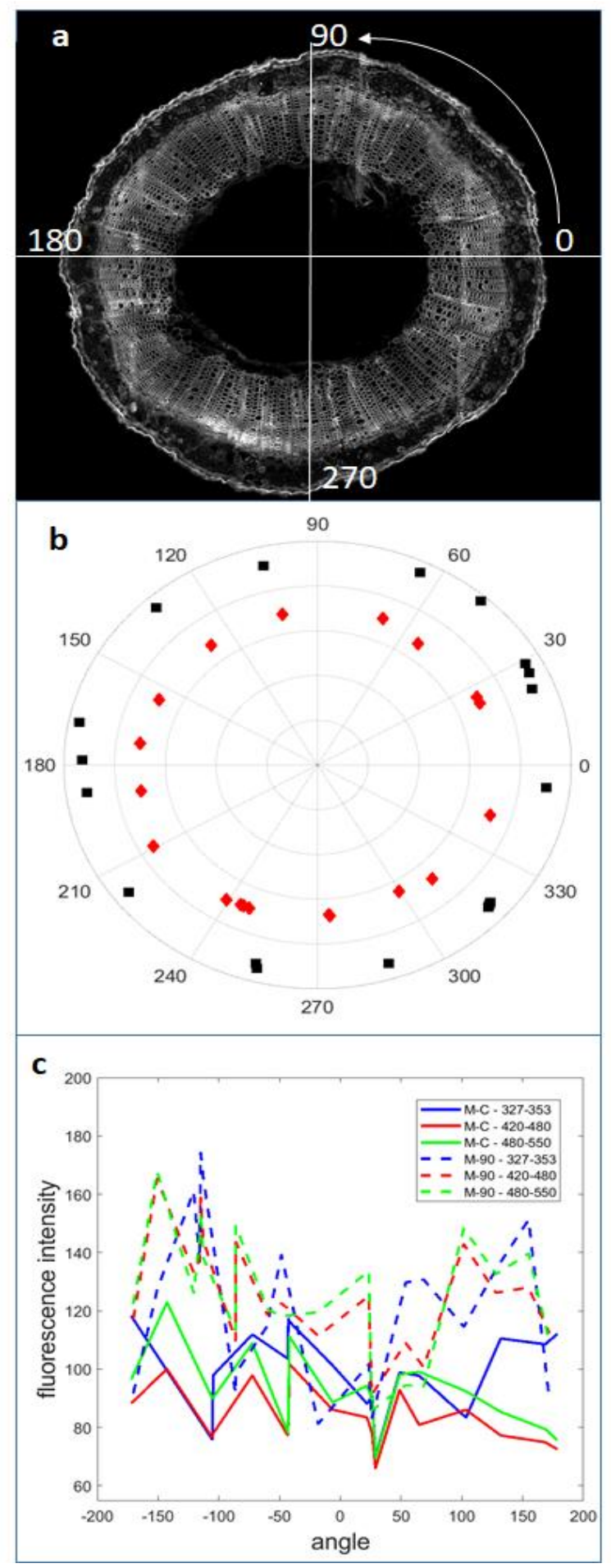




\section{SUPPLEMENTARY MATERIALS}

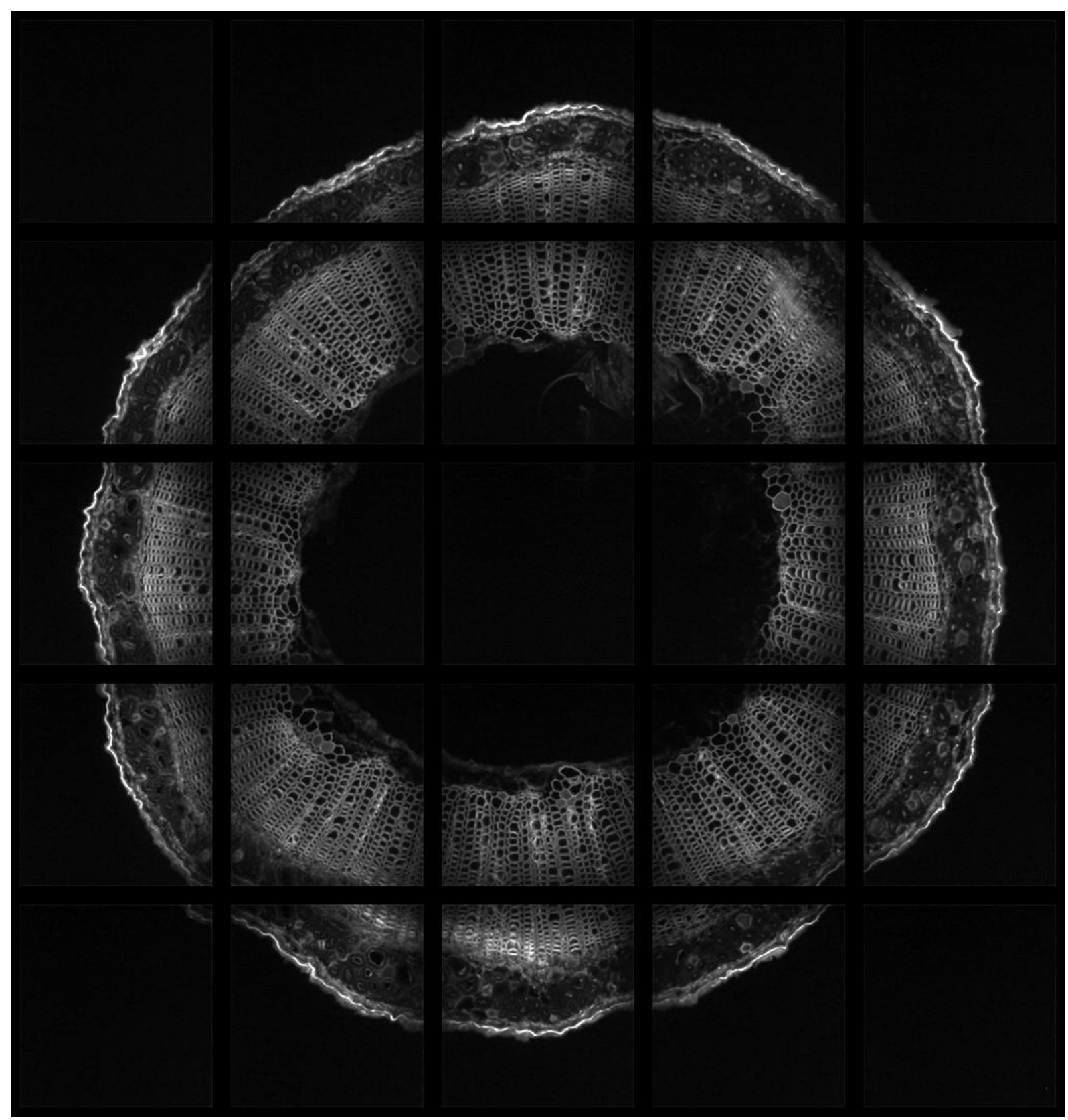

Raw images (mature 90) acquired with a 420-460 nm filter. The 25 individual images are separated by black spaces. There is an overlap of 34 pixels between each contiguous image (approximately 5\%). Min and max values were set to 700 and 1250 for visualization purposes. Individual image size is $444 \times 468$ pixels. 


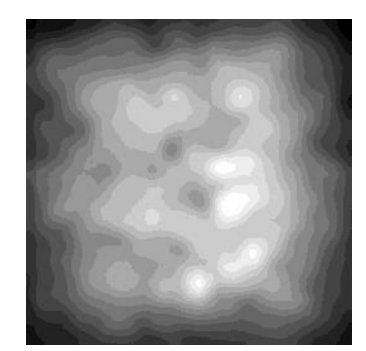

Image computed as the maximum intensities of all individual images recorded with a 420$480 \mathrm{~nm}$ emission filter. Image filtered by 1 - morphological openings (Soille, 2003) using a square of size $25 \times 25$ as the structuring element and 2- average filtering of size $25 \times 25$.

The image size is $444 \times 468$ pixels.

Left: Camera background image acquired with a $420-460 \mathrm{~nm}$ filter after $10 \mathrm{~s}$ of acquisition. Intensities varied between 720 and 745. Right: Reference image for synchrotron beam illumination. Intensities varied between 755 and 9850 . The two images were filtered by 1 median filtering of size $9 \times 9$ pixels to remove spikes and 2 - average filtering of size $25 \times$ 25 pixel for smoothing. The image sizes are 1024 x 1024 pixels. 

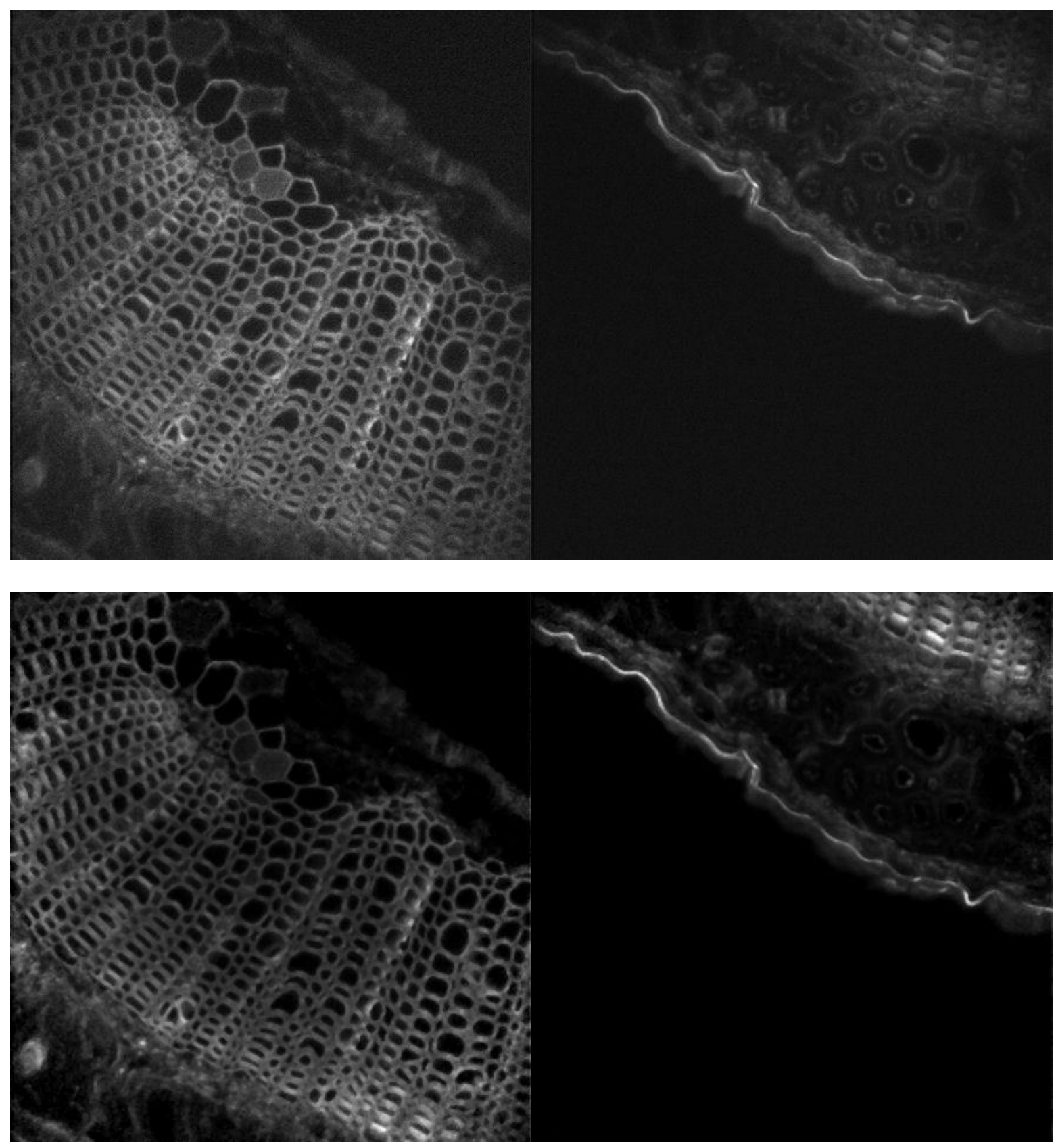

Individual images before (top) and after (bottom) preprocessing. Intensities at the borders of the images are enhanced on the processed images. 


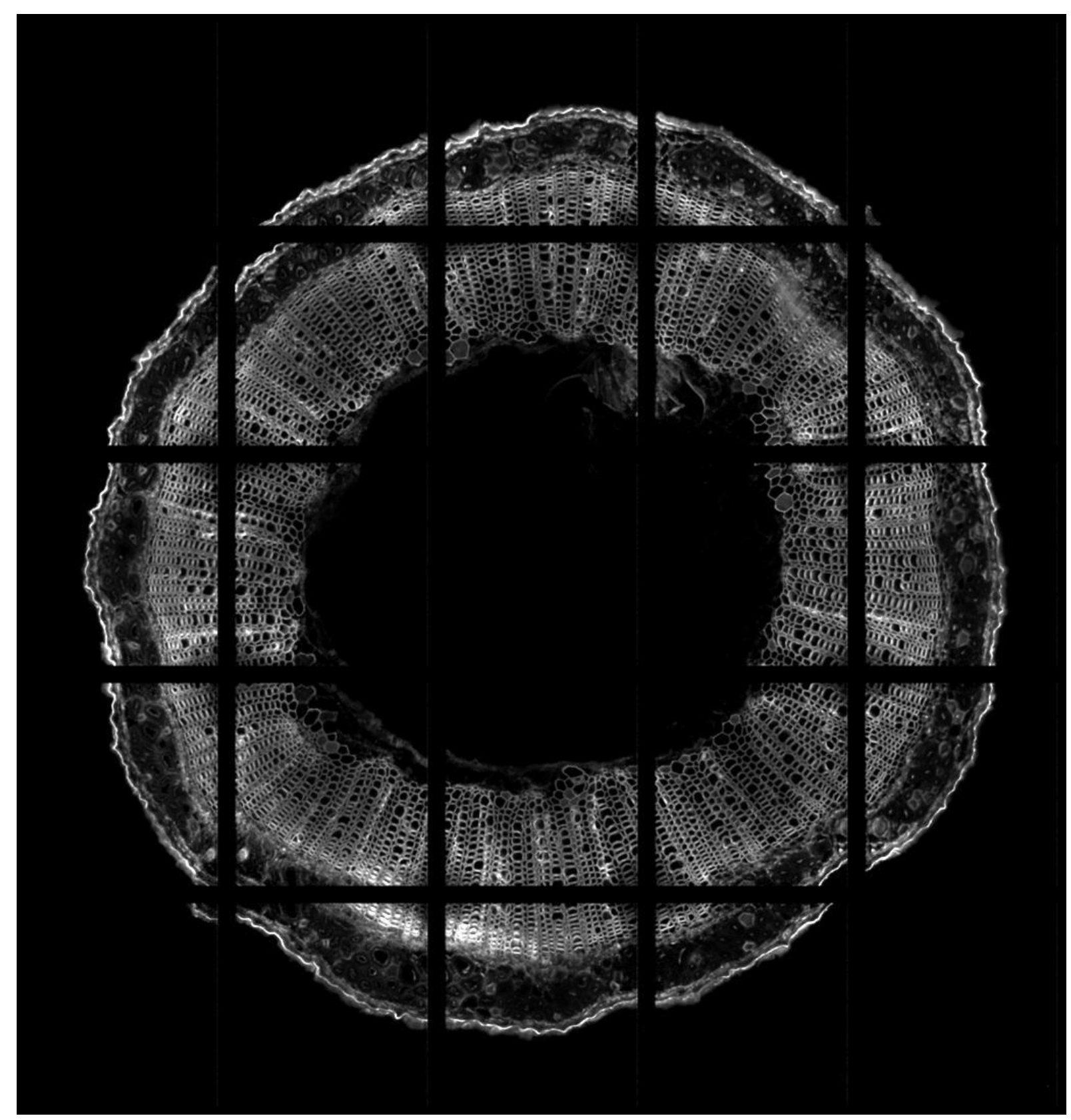

Preprocessed images of (M_90) acquired with a 420-460 nm filter. The 25 individual images are separated by black spaces. There is an overlap of 34 pixels (approximately $5 \%$ ) between each contiguous image. Min and max values were set to 0 and 700 for visualization purposes. The individual image size is $444 \times 468$ pixels. 


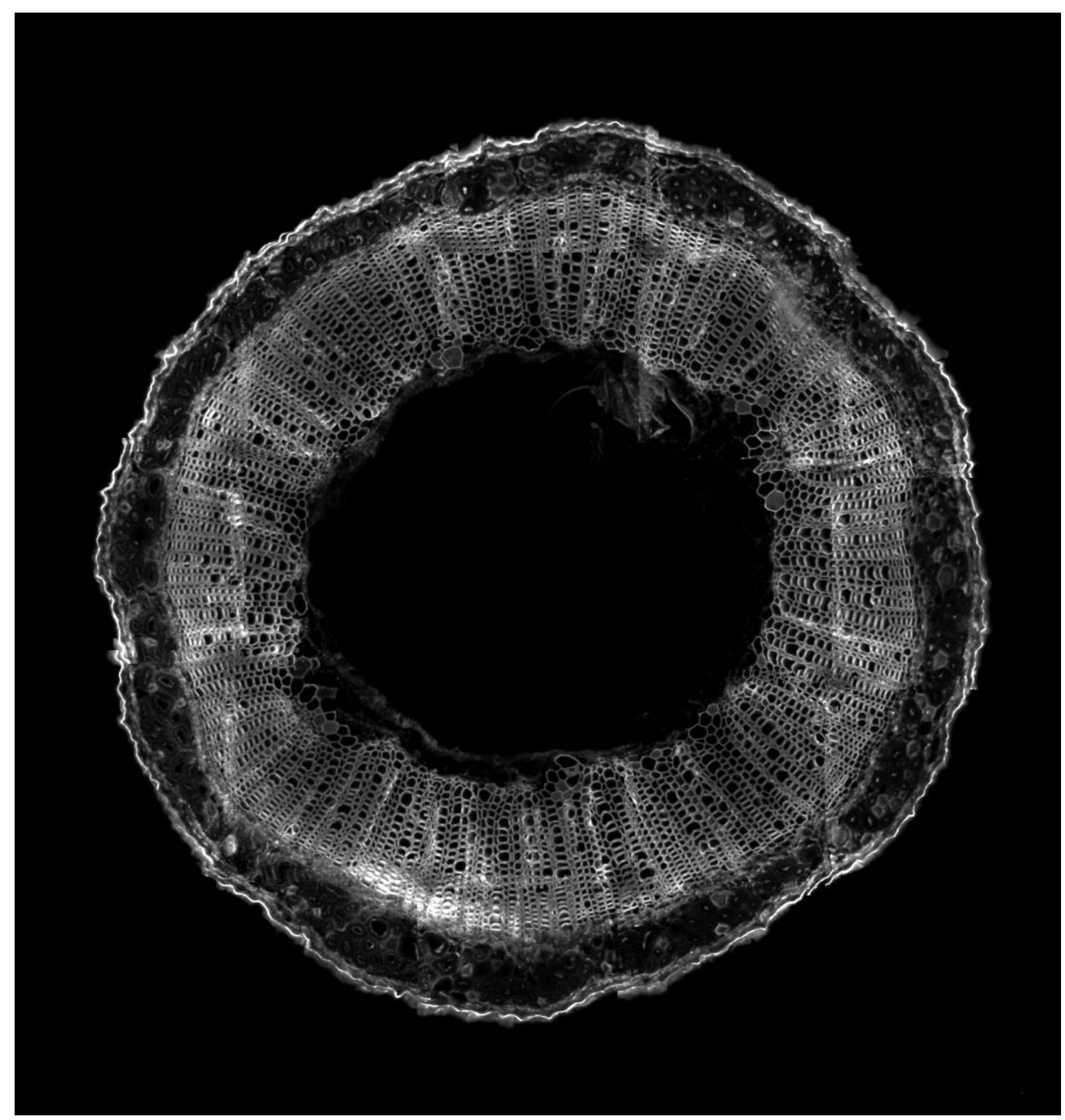

Preprocessed mosaic images of (M_90) acquired with a 420-460 nm filter. Min and max values were set to 0 and 700 for visualization purposes. The image size is $2149 \times 2266$ pixels. 


\section{TABLE}

Table 1: Building colour images from the three emission filters. The same maximum intensity values were set for all images.

\begin{tabular}{|l|l|l|l|l|}
\hline $\begin{array}{l}\text { Channel of the } \\
\text { colour image }\end{array}$ & Filter/bandpass & $\begin{array}{l}\text { Maximum } \\
\text { intensity }\end{array}$ & $\begin{array}{l}\text { Expected } \\
\text { compound }\end{array}$ & Expected colour \\
\hline Blue & $327-353 \mathrm{~nm}$ & 500 & Protein & blue \\
\hline Green & $420-460 \mathrm{~nm}$ & 400 & Hydroxycinnamates & Green to yellow \\
\hline Red & $480-550 \mathrm{~nm}$ & 300 & Lignin & Red to yellow \\
\hline
\end{tabular}




\section{REFERENCES}

Ageeva, M.V., Petrovská, B., Kieft, H., Sal'nikov, V.V., Snegireva, A.V., van Dam, J.E.G., van Veenendaal, W.L.H., Emons, A.M.C., Gorshkova, T.A., van Lammeren, A.A.M., 2005. Intrusive growth of flax phloem fibers is of intercalary type. Planta 222, 565-574.

Akin, D.E., 2013. Linen most useful: perspectives on structure, chemistry, and enzymes for retting flax. ISRN biotechnology 2013, 186534.

Allouche, F., Hanafi, M., Jamme, F., Robert, P., Guillon, F., Devaux, M.F., 2012. Coupling hyperspectral image data having different spatial resolutions by extending multivariate inter-battery Tucker analysis. Chemometrics and Intelligent Laboratory Systems 113, 43-51.

Arnould, O., Siniscalco, D., Bourmaud, A., Le Duigou, A., Baley, C., 2017. Better insight into the nano-mechanical properties of flax fibre cell walls. Industrial Crops and Products 97, 224-228.

Baldacci-Cresp, F., Spriet, C., Twyffels, L., Blervacq, A.-S., Neutelings, G., Baucher, M., Hawkins, S., 2020. A rapid and quantitative safranin-based fluorescent microscopy method to evaluate cell wall lignification. 102, 1074-1089.

Beaugrand, J., Nottez, M., Konnerth, J., Bourmaud, A., 2014. Multi-scale analysis of the structure and mechanical performance of woody hemp core and the dependence on the sampling location. Industrial Crops and Products 60, 193-204.

Bourmaud, A., Beaugrand, J., Shah, D.U., Placet, V., Baley, C., 2018. Towards the design of highperformance plant fibre composites. Progress in Materials Science 97, 347-408.

Bourmaud, A., Gibaud, M., Baley, C., 2016. Impact of the seeding rate on flax stem stability and the mechanical properties of elementary fibres. Industrial Crops and Products 80, 17-25.

Bourmaud, A., Mérotte, J., Siniscalco, D., Le Gall, M., Gager, V., Le Duigou, A., Pierre, F., Behlouli, K., Arnould, O., Beaugrand, J., Baley, C., 2019. Main criteria of sustainable natural fibre for efficient unidirectional biocomposites. Composites Part A: Applied Science and Manufacturing 124, 105504.

Buchanan B., G.W., Jones R. L. , 2002. Biochemistry \& Molecular Biology of Plants, in: Buchanan, G., Jones (Ed.). John Wiley and Sons Ltd.

Chabi, M., Goulas, E., Leclercq, C.C., de Waele, I., Rihouey, C., Cenci, U., Day, A., Blervacq, A.S., Neutelings, G., Duponchel, L., Lerouge, P., Hausman, J.F., Renaut, J., Hawkins, S., 2017. A Cell Wall Proteome and Targeted Cell Wall Analyses Provide Novel Information on Hemicellulose Metabolism in Flax. Molecular \& Cellular Proteomics 16, 1634-1651.

Corbin, C., Decourtil, C., Marosevic, D., Bailly, M., Lopez, T., Renouard, S., Doussot, J., Dutilleul, C., Auguin, D., Giglioli-Guivarc'h, N., Laine, E., Lamblin, F., Hano, C., 2013. Role of protein farnesylation events in the ABA-mediated regulation of the Pinoresinol-Lariciresinol Reductase 1 (LuPLR1) gene expression and lignan biosynthesis in flax (Linum usitatissimum L.). Plant Physiology and Biochemistry 72, 96-111.

Corbin, C., Drouet, S., Markulin, L., Auguin, D., Laine, E., Davin, L.B., Cort, J.R., Lewis, N.G., Hano, C., 2018. A genome-wide analysis of the flax (Linum usitatissimum L.) dirigent protein family: from gene identification and evolution to differential regulation. Plant Molecular Biology 97, 73-101.

Day, A., 2004. La lignification des fibres périphloémiennes du lin (Linum usitatissimum L. ) : approches cytochimique, chimique et moléculaire, pp. 1 vol. (XI-253 f.).

Day, A., Fenart, S., Neutelings, G., Hawkins, S., Rolando, C., Tokarski, C., 2013. Identification of cell wall proteins in the flax (Linum usitatissimum) stem. Proteomics 13, 812-825.

Devaux, M.-F., Jamme, F., André, W., Bouchet, B., Alvarado, C., Durand, S., Robert, P., Saulnier, L., Bonnin, E., Guillon, F., 2018a. Synchrotron Time-Lapse Imaging of Lignocellulosic Biomass Hydrolysis: Tracking Enzyme Localization by Protein Autofluorescence and Biochemical Modification of Cell Walls by Microfluidic Infrared Microspectroscopy. Frontiers in Plant Science 9. 
Devaux, M.F., Jamme, F., Andre, W., Bouchet, B., Alvarado, C., Durand, S., Robert, P., Saulnier, L., Bonnin, E., Guillon, F., 2018b. Synchrotron Time-Lapse Imaging of Lignocellulosic Biomass Hydrolysis: Tracking Enzyme Localization by Protein Autofluorescence and Biochemical Modification of Cell Walls by Microfluidic Infrared Microspectroscopy. Frontiers in Plant Science $9,16$.

Dymińska, L., Gągor, A., Hanuza, J., Kulma, A., Preisner, M., Żuk, M., Szatkowski, M., Szopa, J., 2014. Spectroscopic characterization of genetically modified flax fibers. Journal of Molecular Structure 1074, 321-329.

Edelstein, A., Amodaj, N., Hoover, K., Vale, R., Stuurman, N., 2010. Computer control of microscopes using $\mu$ Manager. Current protocols in molecular biology Chapter 14, Unit14.20.

Frédéric, J., Slavka, K., Sandrine, V., Fatma, A., Stéphane, P., Valérie, R., Matthieu, R., 2013. Deep UV autofluorescence microscopy for cell biology and tissue histology. Biology of the Cell 105, 277288.

Ghislain, B., Clair, B., 2017. Diversity in the organisation and lignification of tension wood fibre walls - A review. Iawa Journal 38, 245-265.

Gierlinger, N., Goswami, L., Schmidt, M., Burgert, I., Coutand, C., Rogge, T., Schwanninger, M., 2008. In situ FT-IR microscopic study on enzymatic treatment of poplar wood cross-sections. Biomacromolecules 9, 2194-2201.

Girault, R., Bert, F., Morvan, O., Vandevelde, M.C., Morvan, C., 1996. Interactions of galactanprotein with cellulose within the secondary deposits of flax fibres. Abstracts of Papers of the American Chemical Society 211, 173-CELL.

Giuliani, A., Jamme, F., Rouam, V., Wien, F., Giorgetta, J.L., Lagarde, B., Chubar, O., Bac, S., Yao, I., Rey, S., Herbeaux, C., Marlats, J.L., Zerbib, D., Polack, F., Refregiers, M., 2009. DISCO: a lowenergy multipurpose beamline at synchrotron SOLEIL. Journal of Synchrotron Radiation 16, 835841.

Gorshkova, T., Mokshina, N., Chernova, T., Ibragimova, N., Salnikov, V., Mikshina, P., Tryfona, T., Banasiak, A., Immerzeel, P., Dupree, P., Mellerowicz, E.J., 2015. Aspen Tension Wood Fibers Contain $\beta$ - $(1 \rightarrow 4)$-Galactans and Acidic Arabinogalactans Retained by Cellulose Microfibrils in Gelatinous Walls. Plant Physiology 169, 2048.

Gorshkova, T.A., Salnikov, V.V., Chemikosova, S.B., Ageeva, M.V., Pavlencheva, N.V., Dam, J.E.G., 2003. The snap point: a transition point in Linum usitatissimum bast fiber development. Ind Crops Prod. 18.

Gorshkova, T.A., Salnikov, V.V., Pogodina, N.M., Chemikosova, S.B., Yablokova, E.V., Ulanov, A.V., Ageeva, M.V., Van Dam, J.E.G., Lozovaya, V.V., 2000. Composition and distribution of cell wall phenolic compounds in flax (Linum usitatissimum L.) stem tissues. Ann. Bot. 85, 477-486.

Gorshkova, T.A., Wyatt, S.E., Salnikov, V.V., Gibeaut, D.M., Ibragimov, M.R., Lozovaya, V.V., Carpita, N.C., 1996. Cell-Wall Polysaccharides of Developing Flax Plants. Plant Physiol 110, 721 729.

Goubet, F., Morvan, C., 1993. Evidence for several galactan synthases in flax (Linum-Usitassimum L) suspension-cultured cells Plant and Cell Physiology 34, 1297-1303.

Goudenhooft, C., Bourmaud, A., Baley, C., 2017. Varietal selection of flax over time: Evolution of plant architecture related to influence on the mechanical properties of fibers. Industrial Crops and Products 97, 56-64.

Goudenhooft, C., Bourmaud, A., Baley, C., 2019a. Flax (Linum usitatissimum L.) Fibers for Composite Reinforcement: Exploring the Link Between Plant Growth, Cell Walls Development, and Fiber Properties. Frontiers in Plant Science 10.

Goudenhooft, C., Bourmaud, A., Baley, C., 2019b. Study of plant gravitropic response: Exploring the influence of lodging and recovery on the mechanical performances of flax fibers. Industrial Crops and Products 128, 235-238. 
Goudenhooft, C., Siniscalco, D., Arnould, O., Bourmaud, A., Sire, O., Gorshkova, T., Baley, C., 2018. Investigation of the Mechanical Properties of Flax Cell Walls during Plant Development: The Relation between Performance and Cell Wall Structure. Fibers 6, 9.

Heer, 1873. Prehistoric Culture of Flax. Nature 7, 453-453.

Heller, K., Sheng, Q.C., Guan, F., Alexopoulou, E., Hua, L.S., Wu, G.W., Jankauskienė, Z., Fu, W.Y., 2015. A comparative study between Europe and China in crop management of two types of flax: linseed and fibre flax. Industrial Crops and Products 68, 24-31.

Himmelsbach, D.S., Khalili, S., Akin, D.E., 1998. FT-IR microspectroscopic imaging of flax (Linum usitatissimum L.) stems. Cellular and molecular biology (Noisy-le-Grand, France) 44, 99108.

Ibragimova, N.N., Ageeva, M.V., Gorshkova, T.A., 2017. Development of gravitropic response: unusual behavior of flax phloem G-fibers. Protoplasma 254, 749-762.

Jamme, F., Bourquin, D., Tawil, G., Vikso-Nielsen, A., Buleon, A., Refregiers, M., 2014. 3D Imaging of Enzymes Working in Situ. Analytical Chemistry 86, 5265-5270.

Jamme, F., Kascakova, S., Villette, S., Allouche, F., Pallu, S., Rouam, V., Réfrégiers, M., 2013. Deep UV autofluorescence microscopy for cell biology and tissue histology. Biol Cell 105.

Le Roy, J., Blervacq, A.S., Creach, A., Huss, B., Hawkins, S., Neutelings, G., 2017. Spatial regulation of monolignol biosynthesis and laccase genes control developmental and stress-related lignin in flax. Bmc Plant Biology 17, 20.

Li, Y., Hu, Y.-S., Li, H., Chen, L., Huang, X., 2016. A superior low-cost amorphous carbon anode made from pitch and lignin for sodium-ion batteries. Journal of Materials Chemistry A 4, 96-104.

Liao, Y., Koelewijn, S.-F., Van den Bossche, G., Van Aelst, J., Van den Bosch, S., Renders, T., Navare, K., Nicolaï, T., Van Aelst, K., Maesen, M., Matsushima, H., Thevelein, J.M., Van Acker, K., Lagrain, B., Verboekend, D., Sels, B.F., 2020. A sustainable wood biorefinery for low-carbon footprint chemicals production. 367, 1385-1390.

Lion, C., Simon, C., Huss, B., Blervacq, A.S., Tirot, L., Toybou, D., Spriet, C., Slomianny, C., Guerardel, Y., Hawkins, S., Biot, C., 2017. BLISS: A Bioorthogonal Dual-Labeling Strategy to Unravel Lignification Dynamics in Plants. Cell chemical biology 24, 326-338.

Maréchal, Y., Chanzy, H., 2000. The hydrogen bond network in I $<\mathrm{SUB}>\beta</ \mathrm{SUB}>$ cellulose as observed by infrared spectrometry. 523, 183.

Mikshina, P.V., Gurjanov, O.P., Mukhitova, F.K., Petrova, A.A., Shashkov, A.S., Gorshkova, T.A., 2012. Structural details of pectic galactan from the secondary cell walls of flax (Linum usitatissimum L.) phloem fibres. Carbohydrate Polymers 87, 853-861.

Mnich, E., Bjarnholt, N., Eudes, A., Harholt, J., Holland, C., Jørgensen, B., Larsen, F.H., Liu, M., Manat, R., Meyer, A.S., Mikkelsen, J.D., Motawia, M.S., Muschiol, J., Møller, B.L., Møller, S.R., Perzon, A., Petersen, B.L., Ravn, J.L., Ulvskov, P., 2020. Phenolic cross-links: building and deconstructing the plant cell wall. Natural Product Reports.

Mohanty, A.K., Vivekanandhan, S., Pin, J.-M., Misra, M., 2018. Composites from renewable and sustainable resources: Challenges and innovations. Science 362, 536-542.

Monties, B., 1989. Molecular structure and biochemical properties of lignins in relation to possible self-organization of lignin networks, Annales des sciences forestières. EDP Sciences, pp. 848s-855s. Nuez, L., Beaugrand, J., Shah, D.U., Mayer-Laigle, C., Bourmaud, A., D’Arras, P., Baley, C., 2020. The potential of flax shives as reinforcements for injection moulded polypropylene composites. Industrial Crops and Products 148, 112324.

Ray F. Evert, S.E.E., 2006. Esau's Plant Anatomy: Meristems, Cells, and Tissues of the Plant Body: Their Structure, Function, and Development, 3rd Edition. 624.

Réquilé, S., Goudenhooft, C., Bourmaud, A., Le Duigou, A., Baley, C., 2018. Exploring the link between flexural behaviour of hemp and flax stems and fibre stiffness. Industrial Crops and Products 113, 179-186.

Rihouey, C., Paynel, F., Gorshkova, T., Morvan, C., 2017. Flax fibers: assessing the non-cellulosic polysaccharides and an approach to supramolecular design of the cell wall. Cellulose 24, 1985-2001. 
Scalbert, A., Monties, B., Lallemand, J.-Y., Guittet, E., Rolando, C.J.P., 1985. Ether linkage between phenolic acids and lignin fractions from wheat straw. 24, 1359-1362.

Soille, P., 2003. Morphological image analysis. Springer, Berlin.

Stewart, D., McDougall, G.J., Baty, A., 1995. Fourier-Transform Infrared Microspectroscopy of Anatomically Different Cells of Flax (Linum usitatissimum) Stems during Development. Journal of Agricultural and Food Chemistry 43, 1853-1858.

Tomazevic, D., Likar, B., Pernus, F., 2002. Comparative evaluation of retrospective shading correction methods. Journal of microscopy 208, 212-223.

Viala, R., Placet, V., Cogan, S., 2018. Identification of the anisotropic elastic and damping properties of complex shape composite parts using an inverse method based on finite element model updating and 3D velocity fields measurements (FEMU-3DVF): Application to bio-based composite violin soundboards. Composites Part a-Applied Science and Manufacturing 106, 91-103. 